\title{
New Australasian and Oriental Triaenodes species (Trichoptera: Leptoceridae)
}

\author{
J. OLÁH \\ János Oláh, H-4032 Debrecen, Tarján u. 28, Hungary. Email: profolah@gmail.com
}

\begin{abstract}
The following new species are described from the long-horned caddisfly genera Triaenodes McLachlan, 1865; Vietnam: T. catbana, T. sokaga; Indonesia (Sumba Island): T. sumbana; Indonesia (Batanta Island): T. apraka, T. bala, T. harmasa, T. izgaga, T. jobba, T. kalija, T. marleorum, T. nemapraka, T. sagodii, T. sarla, T. torpa, T. tudarda, T. zugora; Indonesia (Papua): T. atkarol, T. fodra, T. hasa, T. lemeza, T. tarula, T. zicsii; Solomon Islands: T. fura, T. gerela, T. picinka; New Hebrides: T. fioka, T. nakla; Fiji Islands: T. bunka, T. buzoga, T. ketaga, T. koba, T. ranca. Triaenodes dusra Schmid described from China has been recorded from Malaysia and Vietnam. Triaenodes pellectus Ulmer described from Japan has been recorded from Vietnam. Triaenodes pentheus Malicky described from Thailand has been recorded from Vietnam. Phylogenetic relation of Triaenodes paratlan Oláh \& Mey described from Indonesia (Papua) has been revised.
\end{abstract}

Keywords. Vietnam, Pacific Islands, Melanesia, Fiji Islands, New Hebrides, Solomon Islands, Triaenodes, new Species

\section{INTRODUCTION}

$\mathrm{T}$ he caddisfly fauna of the Melanesia group of the Pacific Islands is poorly known. Especially New Guinea, the last unexplored island remained still virgin; huge territories are almost untouched by caddisfly collectors. In a recent taxonomic list of the Trichoptera described and recorded from New Guinea region we have registered altogether 352 species (Oláh 2012a). The high diversity of the island is documented by 338 endemic species, those described newly from the region, with a very tiny effort of collection. In the last few years we have devoted special effort to collect caddisflies in the Batanta Island of New Guinea. Between the years of 2010 and 2016 we have organised 9 field collecting expeditions financed by Hungarian bird-watching, bird photography, and scuba diving tourist industries. One expedition to the Arfak and Snow Mountains, West Papua was organised, financed and realised by Robert Horváth from the Papua Paradise EcoResort (Birie Island, Raja Ampat, Papua, Indonesia) and Nature Discovery Fund (KisarHungary). Here we elaborate all the specimens and describe the new species of the long-horned caddisfly genus Triaenodes collected during these expeditions as well as some other materials collected earlier partly by the author in Vietnam, Indonesia (Sumba Island), Solomon Islands, New Hebrides and Fiji Islands.

\section{MATERIAL AND METHODS}

We have installed UV light traps as well as collected specimens from white sheet illuminated by Honda generator or by battery powered lamps. The material including all holotypes and paratypes are preserved in 70-80\% alcohol and deposited in the collection of the author under presented property of the Hungarian Natural History Museum (OPC) or in the Naturalis Biodiversity Center - Zoological Museum, Amsterdam, Netherlands (NBC-ZMAN) and in the British Natural History Museum (NHM).

\section{TAXONOMY}

\section{Triaenodes aproka sp. nov.}

(Figures 1-2)

Material examined. Holotype. Indonesia, Papua Barat, Batanta Island, Northern cost, Warmon stream, $0^{\circ} 48^{\prime} 1.52$ "'S, $130^{\circ} 70 " 8.10^{\prime \prime} \mathrm{E}$, above se- 
cond waterfall, 22.01.2013, light trap, leg R. Horváth (1 male, OPC). Paratypes. Papua Barat, Batanta Island, Northern coast, small stream with dry mouth: 0'49'27.84'S 130'38"45.02"E, 1000$1500 \mathrm{~m}$ above dry mouth, 28.01.2012, light trap, leg R. Horváth (1 male, OPC). Papua Barat, Batanta Island, valley of Warmon Stream, upper waterfall, $0^{\circ} 50$ '23.25' S, 130 $42^{\prime} 35.18^{\prime \prime} \mathrm{E}, 150 \mathrm{~m}$, 20.01.2014, at light, leg. T. Kovács, P. Juhász (1 male, OPC). Papua Barat, Batanta Island, Teluk Warai, stream, $0^{\circ} 50^{\prime} 51.0^{\prime \prime} \mathrm{S}, 130^{\circ} 35^{\prime} 14.0^{\prime \prime} \mathrm{E}$, 11.II.2015, at light, T. Kovács, P. Juhász (1 male, OPC). Papua Barat, Batanta Island, right side stream of Forum River, $0^{\circ} 52^{\prime} 22.7^{\prime \prime}, 130^{\circ} 27^{\prime}$ 45.1", 13.02.2015, at light, T. Kovács, R. Horváth, P. Juhász (1 male, OPC).

Diagnosis. The basic architecture of the genitalia, and particularly the dorsum of segment IX with suture separated tergum, is similar to T. hasa sp. nov. T. paratlan Oláh \& Mey, T. telefomicus Kumanski. However the left mesal basodorsal process is present, not lost. Therefore this tiny species is probably the ancestral species of the lineage of the above mentioned three species with lost left mesal basodorsal process.
Description. Male (in alcohol). Brown animal, Scape slightly enlarged, without discernible scent organ; pedicel short, third segment long. Maxillary palp formula IV-I-II-III-V. Spur formula $1,2,2$. Wing membrane pale yellowish, without any pattern and without any scent setae; forewing length $4 \mathrm{~mm}$.

Male genitalia. Segment IX synsclerotized, subtriangular in lateral view; well-sclerotized frame of sutures encircles the very small tergite IX subdivided into three facets, as visible in dorsal view. Segment $X$ comprising of filiform mesal process (upper process of segment $\mathrm{X}$ ). Cerci setose filiform, half long as the segment X. Paraproct (lower process of segment X) forming a less sclerotized long mesal process. Gonopods bilobed apicad; upper lobe long arching digitiform, lower lobe shorter; a pair of mesal basodorsal process present curving upward and downward. Phallic organ with dilated membranous apical portion of the aedeagus; phallobase connected with a pair of lateral sclerotized strips to sclerotized strips produced discontinuity in ventrum IX.

Etymology. aproka, from "apróka" tiny in Hungarian, refers to small size.

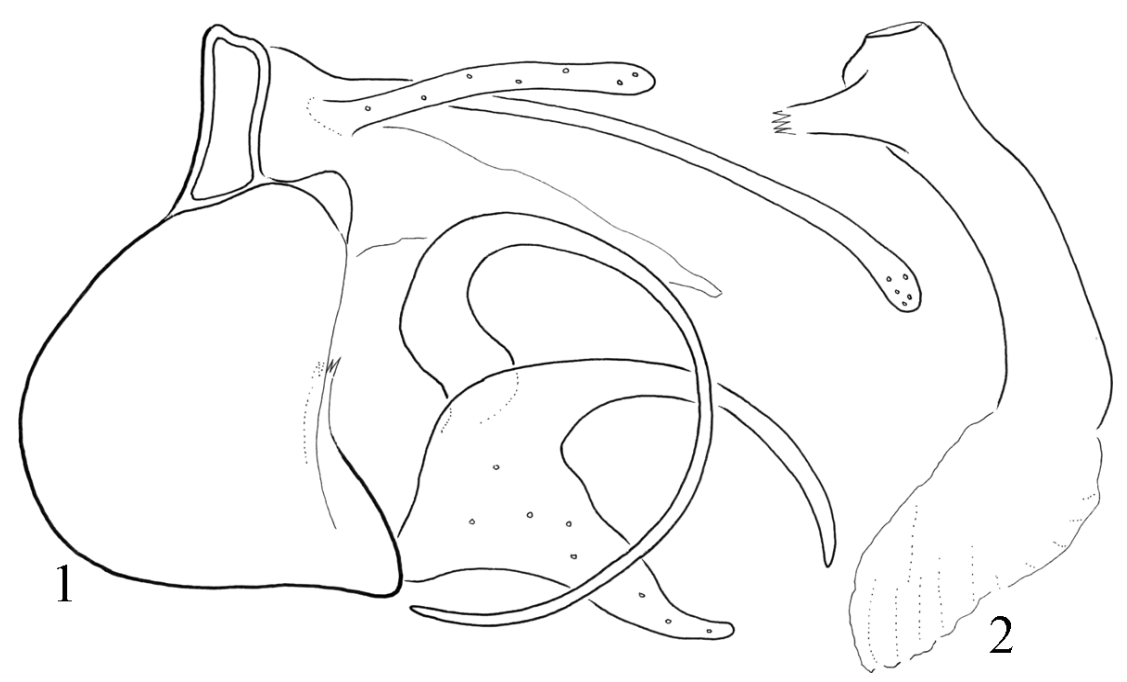

Figures 1-2. Triaenodes aproka sp. nov. Male holotype, $1=$ genitalia in left lateral view, without phallic organ, $2=$ phallic organ in left lateral view. 
Triaenodes atkarol sp. nov.

(Figures 3-6)

Diagnosis. This new species shares similarities in the basic form of segment IX, segment X (upper part of segment X of Yang \& Morse (1993)), paraproct (lower part of segment $\mathrm{X}$ of Yang \& Morse (1993)), and gonopods of the T. bernaysae complex described from Australia by Neboiss and Wells (1998). The basodorsal process is lobose, curving posteriad and foot-shaped. Most close to the nominate species $T$. bernaysae Korboot, but differs by particular organisation of the above listed structures.

Material examined. Holotype. Indonesia, Papua Barat, Birdshead Peninsula, Neney Valley, Arfak, Benyas, $1^{\circ} 27^{\prime} \mathrm{S} 134^{\circ} 01^{\prime} \mathrm{E}, 722 \mathrm{~m}, 17.11$. 2011, leg. Papua Insect Foundation (1 male, NBC-ZMAN).

Description. Male (in alcohol). Pale animal. Scapus enlarged, second segment short, third segment long without any hair pencil of scent organ. Maxillary palp fomula IV-I-II-III-IV. Spur formula 1,2,2. Wing membrane pale yellowish, without any pattern; forewing length $8 \mathrm{~mm}$.

Male genitalia. Segment IX subdivided by incomplete modified suture, producing a very narrow and high tergite and a low double long sternite; the lateral groove is vertical; a very pronounced pair of sclerotized strip, a chitinized support arisen from the dorsodistal region of sternite IX to the phallobase. Segment X organised into a long digitiform, apically setose median lobe. Paraproct bifid with mesad curving, "embracing" lateral arms; the most developed structure guiding the phallic organ dorsad. Cerci setose foliform. Gonopods broad base comprised of lateral finger-like process and a pair of basodorsal lobe with transversally directed terminal setose plate. Phallic organ uniform in diameter, curved downward and supplied with a single spine-like paramere.

Etymology. atkarol, from "átkarol" or "ölel" embrace in Hungarian, refers to the apical shape of paraproct in dorsal view.
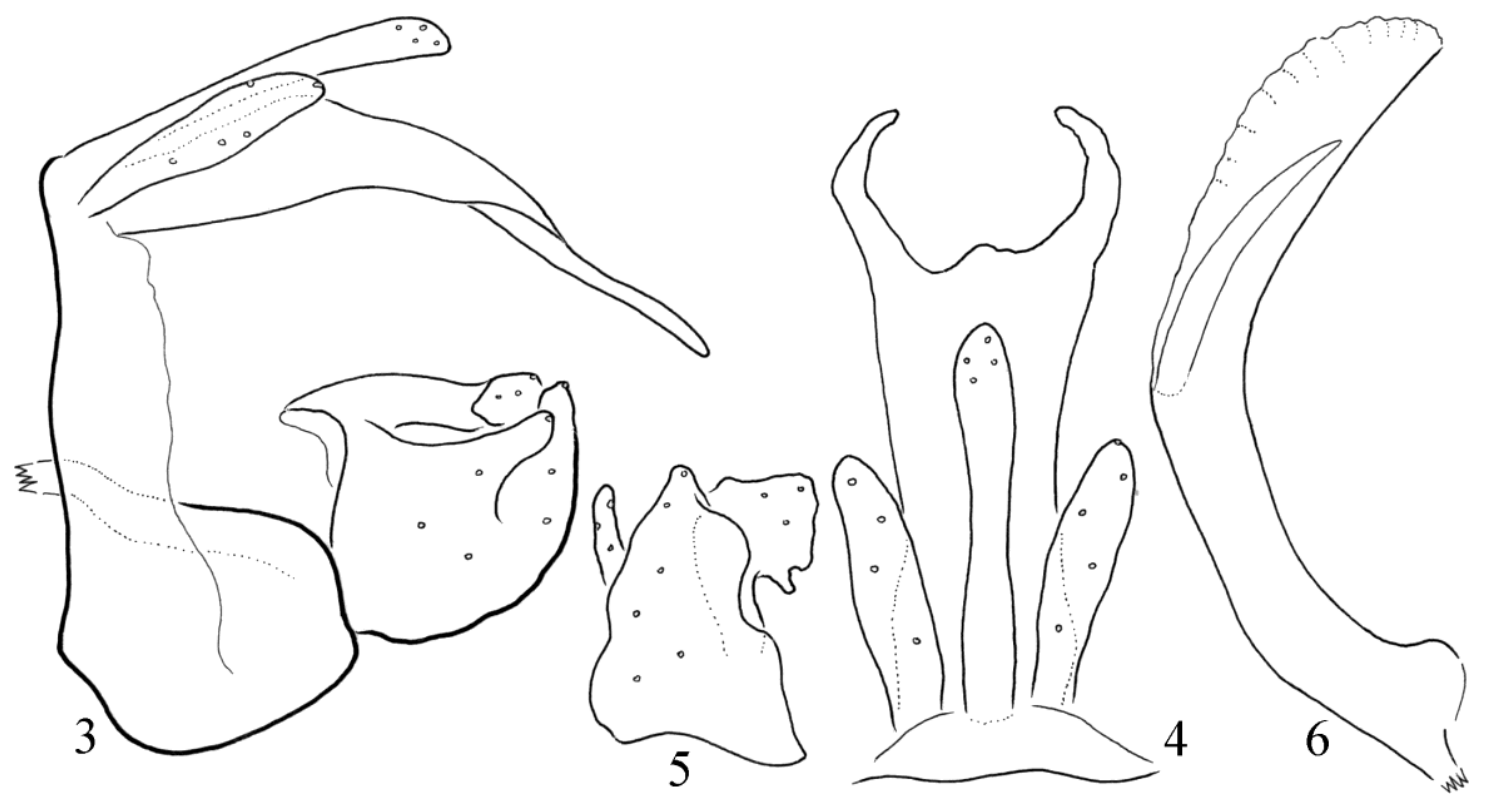

Figures 3-6. Triaenodes atkarol sp. nov. Male holotype, $3=$ genitalia in left lateral view, without phallic organ, $4=$ genitalia in dorsal view, $5=$ left gonopod in ventral view. $6=$ phallic organ in left lateral view. 


\section{Triaenodes bala sp. nov.}

(Figures 7-9)

Diagnosis. Having the left mesal basodorsal process present and the right process is lost this new species differs from the sibling species $T$. telefomicus Kumanski and T. paratlan Oláh \& Mey, T. hasa sp. nov. The mesal basodorsal process has no subapical arm present at T. telefomicus and $T$. paratlan, moreover having dilatation on the basal third of the process $T$. bala sp. nov. is closer to T. hasa sp. nov., but differs by the lateral profile of the mesal basodorsal process and of the phallic organ.

Material examined. Holotype. Indonesia, $\mathrm{Pa}-$ pua Barat, Batanta Island, Northern coast, Warmon stream, $0^{\circ} 50^{\prime} 8.52 " \mathrm{~S}, \quad 130^{\circ} 42^{\prime} 50.4 " \mathrm{E}$, below first waterfall, 22.01.2013, light trap, leg R. Horváth (1 male, OPC). Paratype. Papua Barat, Batanta Island, Kalijakut River, $0^{\circ} 52^{\prime} 49.1^{\prime \prime}$, $130^{\circ} 38^{\prime} 4.9$ ", 16.02.2015, UV light-trap, leg. T. Kovács, P. Juhász, (1 male, OPC).

Description. Male (in alcohol). Brown animal, Scape enlarged, with scent organ of long black setae accompanied by a long flap; pedicel short, third segment long. Maxillary palp fomula IV-III-III-V. Spur formula 1,2,2. Wing membrane pale yellowish, without any pattern; forewing length 6 $\mathrm{mm}$.
Male genitalia. Segment IX synsclerotized, subtriangular in lateral view; well-sclerotized frame of sutures encircles the very small tergite IX subdivided into two facets, as visible in dorsal view. Segment $X$ comprising of filiform trifid mesal process (upper process of segment $\mathrm{X}$ ); the median arm of the trifid mesal process as long as the lateral processes; lateral processes with mesad turning capitate apex, a pair of short, bare digitate process present basodorsad. Cerci setose filiform, as long as the lateral processes of segment $\mathrm{X}$. Paraproct (lower process of segment X) forming a short subtriangular plate with chalazae basad and setae apicad. Gonopods bilobed apicad; upper lobe digitiform, lower lobe lobate; right mesal basodorsal process lost, left mesal basodorsal process of the basal plate of gonopods curving upward, downward and rightward, dilated or bellied one third subbasad. Phallic organ with extremely developed high right ridge; phallobase connected with a pair of lateral sclerotized strips to ventroapical corner of segment IX; this sclerotized strips produced discontinuity in ventrum IX.

Etymology. bala from "bal, balos" left in Hungarian, refers to the left mesal basodorsal process of the basal plate on the gonopods present contrary to the other sibling species having the right process present and the left process lost.
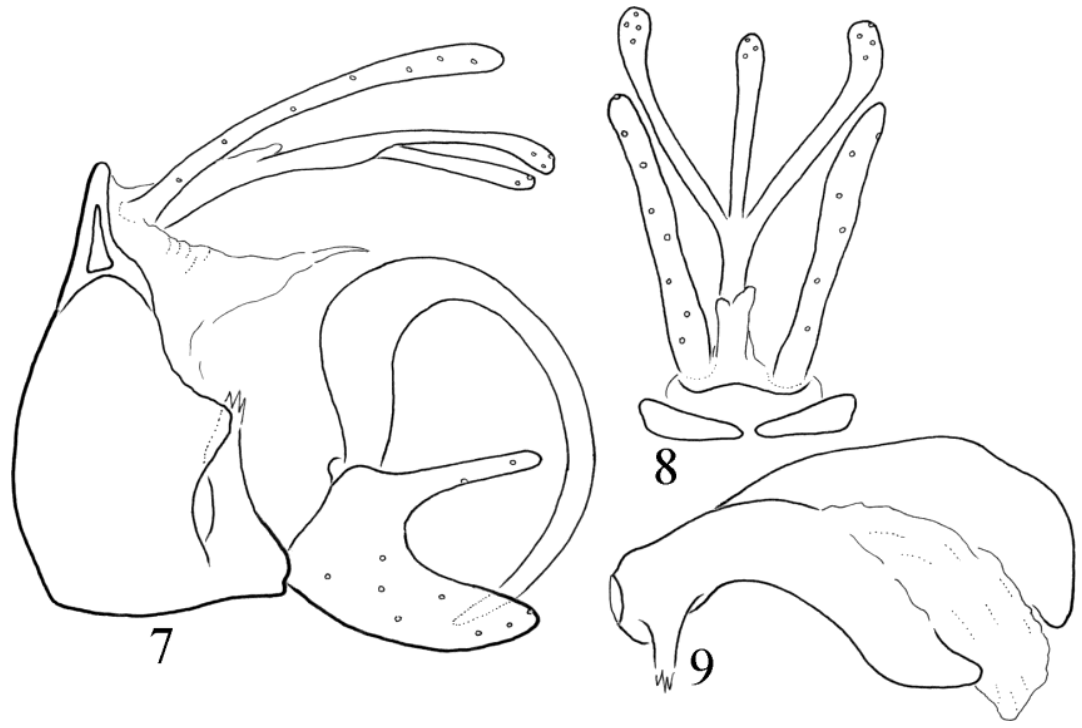

Figures 7-9. Triaenodes bala sp. nov. Male holotype, $7=$ genitalia in left lateral view, without phallic organ, $8=$ genitalia in dorsal view, $9=$ phallic organ in left lateral view. 
Triaenodes bunka sp. nov.

(Figures 10-13)

Diagnosis. Close to T. rebellus Eriksson \& Johanson, but most close to T. buzoga sp. nov., but differs by having segment $\mathrm{X}$ with almost capitate apex, not clavate; apical margin of gonopode truncate, not rounded; mesal basodorsal process differently shaped; lateral flank on aedeagus low, not high.

Material examined. Holotype. Fiji Islands, Viti Levu, Mt. Victoria, 24.11.1970, leg H. S. \& G. S. Robinson (1 male, NHM).

Description. Male (in alcohol). Brown animal, Scape enlarged, without discernible scent organ; pedicel short, third segment long. Maxillary palp fomula IV-I-II-III-V. Spur formula 1,2,2. Wing membrane pale yellowish, without any pattern; forewing length $9 \mathrm{~mm}$.

Male genitalia. Segment IX synsclerotized, the subdivided sternum with its posterior partially detached unit giving support to the phallobase by its sclerotized strips. Segment $X$ (upper process of segment $X$ ) filiform with almost capitate apex. Cerci setose filiform, shorter than segment $X$. Paraproct (lower process of segment $\mathrm{X}$ ) forming a pair of long filiform spine-like processes. There is a single asymmetric spine like shorter sclerotized pointed process attached to paraproct basement. Gonopods bilobed, apical margin oblique truncate; mesal basodorsal process of the basal plate of gonopods short capitate. Phallic organ forming a downward curving tube with membranous apex, phallotheca with low lateral flank.

Etymology. bunka from "bunkó" clavate in Hungarian, refers to club-shaped, clavate, almost capitate apex of segment $\mathrm{X}$.

\section{Triaenodes buzoga sp. nov.}

(Figures 14-17)

Material examined. Holotype. Fiji Islands, Viti Levu, Savura Creek, 31.VII.1975, M. V. light leg. P. A. Maddison (1 male, NHM).

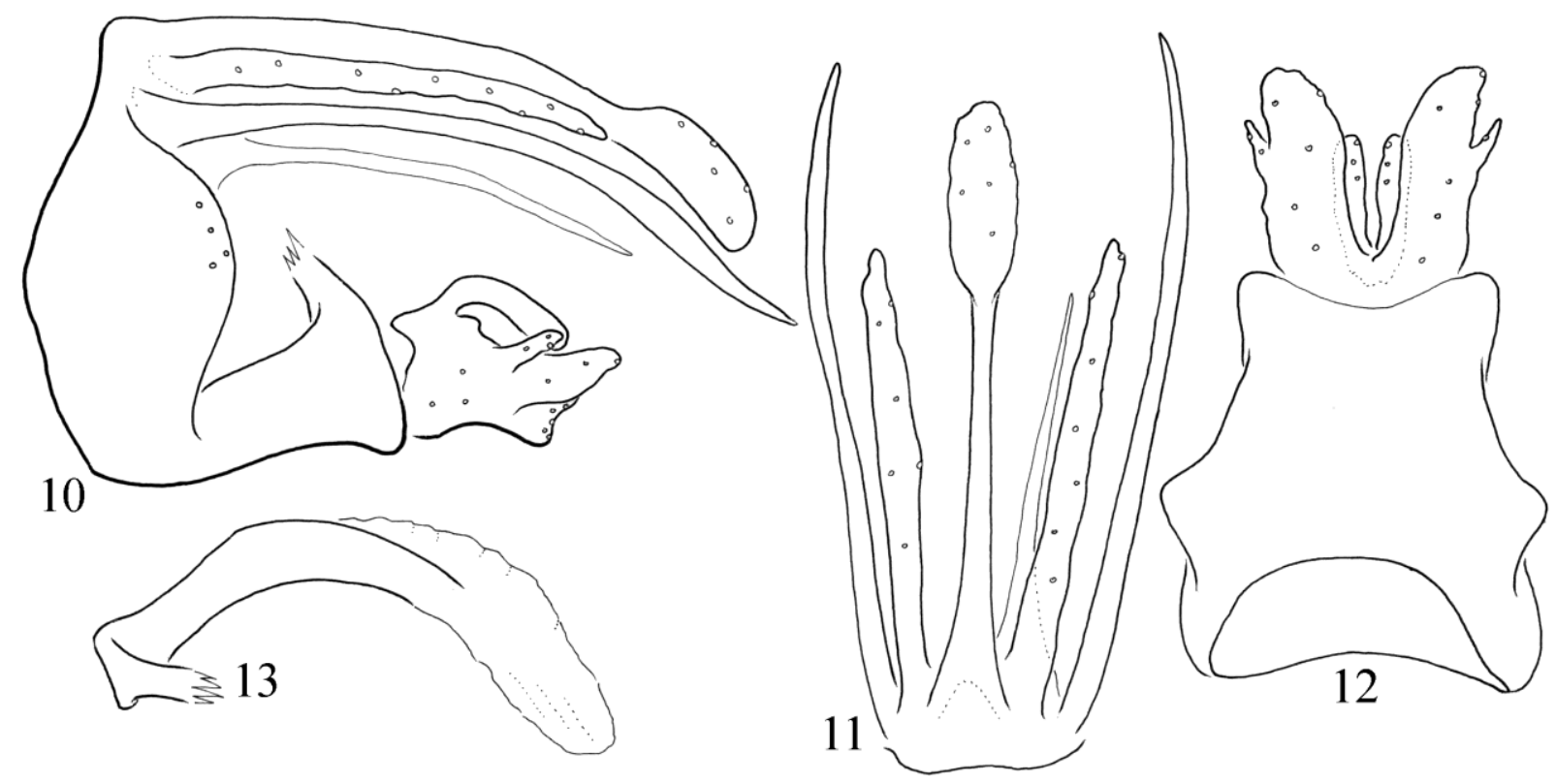

Figures 10-13. Triaenodes bunka sp. nov. Male holotype, $10=$ genitalia in left lateral view, without phallic organ, $11=$ genitalia in dorsal view, 12 = genitalia in ventral view, 13 = phallic organ in left lateral view. 
Diagnosis. Most close to T. bunka sp. nov., but differs by having segment $\mathrm{X}$ with clavate apex; mesal basodorsal process differently shaped; lateral flank on aedeagus high, not low.

Description. Male (in alcohol). Brown animal, Scape enlarged, without discernible scent organ.; pedicel short, third segment long. Maxillary palp fomula IV-I-II-III-V. Spur formula 1,2,2. Wing membrane pale yellowish, without any pattern; forewing length $8 \mathrm{~mm}$.

Male genitalia. Segment IX synsclerotized, the subdivided sternum with its posterior partially detached unit giving support to the phallobase by its sclerotized strips. Segment X (upper process of segment X) filiform with clavate apex. Cerci setose filiform, shorter than segment X. Paraproct (lower process of segment $\mathrm{X}$ ) forming a pair of long filiform spine-like processes. There is a single, asymmetric spine like, shorter, sclerotized pointed process attached to paraproct basement. Gonopods bilobed, apical margin rounded; mesal basodorsal process of the basal plate of gonopods with downward curving apex. Phallic organ forming a downward arching tube with membranous apex, phallotheca with high lateral flank.

Etymology. buzoga from "buzogányos" clavate in Hungarian, refers to club-shaped, apex of segment X.

Triaenodes catbana sp. nov.

(Figures 18-21)

Diagnosis. Has similarity to $T$. narkissos Malicky, 2005 described from Thailand, but differs by having segment $\mathrm{X}$ deeply divided, differently shaped gonopods and mesal basodorsal process short, not long.

Material examined. Holotype. Vietnam, Cat Ba Island, Goi stream, 17.05.1987, singled leg. J. Oláh (1 male, OPC).

Description. Male (in alcohol). Brown animal. Scape enlarged, without discernible scent organ; pedicel short, third segment long. Maxillary palp fomula IV-I-II-III-V. Spur formula 1,2,2. Wing membrane pale yellowish, without any pattern; forewing length $7 \mathrm{~mm}$.

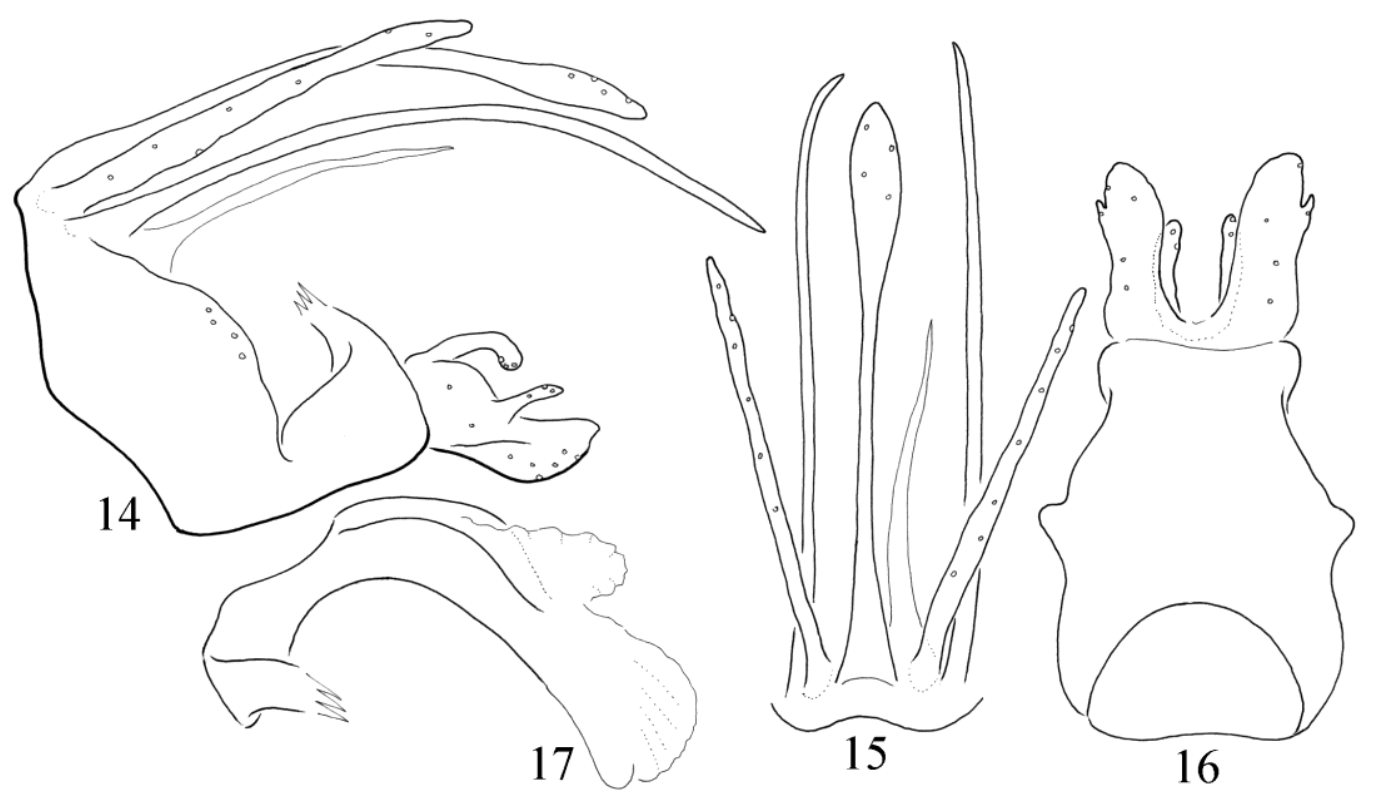

Figures 14-17. Triaenodes buzoga sp. nov. Male holotype, 14 = genitalia in left lateral view, without phallic organ, 15 = genitalia in dorsal view, 16 = genitalia in ventral view, 17 = phallic organ in left lateral view. 


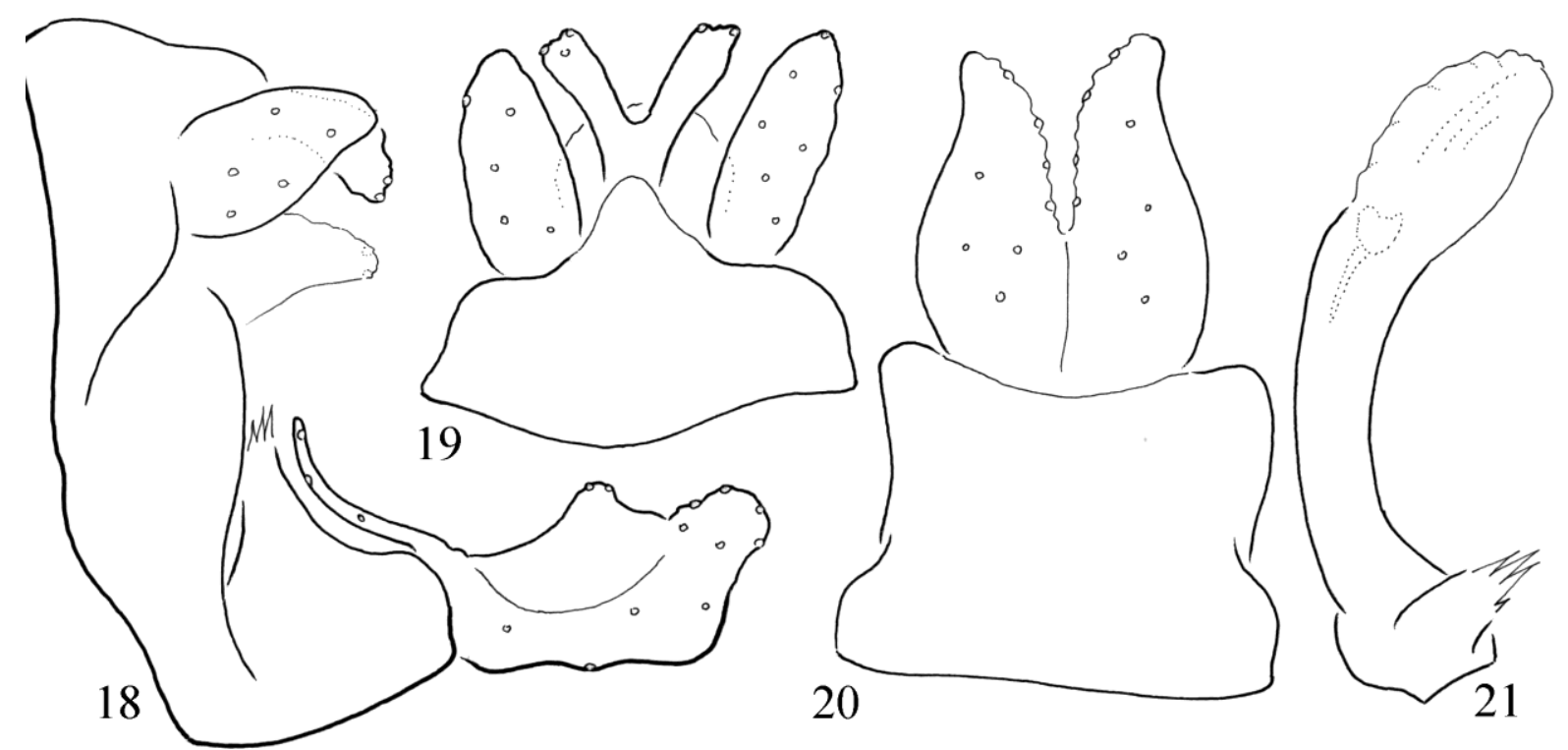

Figures 18-21. Triaenodes catbana sp. nov. Male holotype, $18=$ genitalia in left lateral view, without phallic organ, $19=$ genitalia in dorsal view, 20 = genitalia in ventral view, 21 = phallic organ in left lateral view.

Male genitalia. Segment IX synsclerotized with an oblique suture demarking ventrum of tergite IX; the subdivided sternum with its posterior partially detached unit giving support to the phallobase by its sclerotized strips. Segment $X$ (upper process of segment $\mathrm{X}$ ) short and bifid. Cerci short broad foliform. Paraproct (lower process of segment $\mathrm{X}$ ) fused basally forming a short hood over the phallic organ with indiscernible apex. Apical lobe of gonopods tapering apicad in ventral view. Mesal basodorsal process of the basal plate of gonopods slender, very thin, and short. Phallic organ forming a downward curving tube with membranous apex.

Etymology. catbana, named for the type locality.

\section{Triaenodes dusra Schmid, 1965}

Material examined. Malaysia, Perak, Temengor Lake, 6.12.1993, light leg. G. S. Robinson (1 male, OPC). Vietnam, Moc Chau, 25.10.1986 light leg. J. Oláh (1 male, 1 female; OPC). Bach Thai Province, Quang Chu, 24-25.05.1987, light leg. J. Oláh (6 males, OPC).

\section{Triaenodes fioka sp. nov.}

(Figures 22-25)

Diagnosis. Most close to T. nakla sp. nov., but differs by having left arm of paraproct symmetrical with the right arm, not modified with apical third downward and mesad turning; paraproct basement with ventral process; apical margin of gonopods diverged laterad, not rounded in ventral view; mesal basodorsal process slender, not robust.

Material examined. Holotype. New Hebrides, Santo, Mt Tabwemasana, Nokowula Vill., 3700', 1-4.09.1971, leg G. S. Robinson, Royal Soc. New Hebrides, 1971 (1 male, NHM). Paratype. same as holotype ( 5 males, 7 females, NHM; 3 males, 2 females OPC).

Description. Male (in alcohol). Brown animal. Scape enlarged, without discernible scent organ; pedicel short, third segment long. Maxillary palp fomula IV-I-II-III-V. Spur formula 1,2,2. Wing membrane pale yellowish, without any pattern; forewing length $7 \mathrm{~mm}$. 


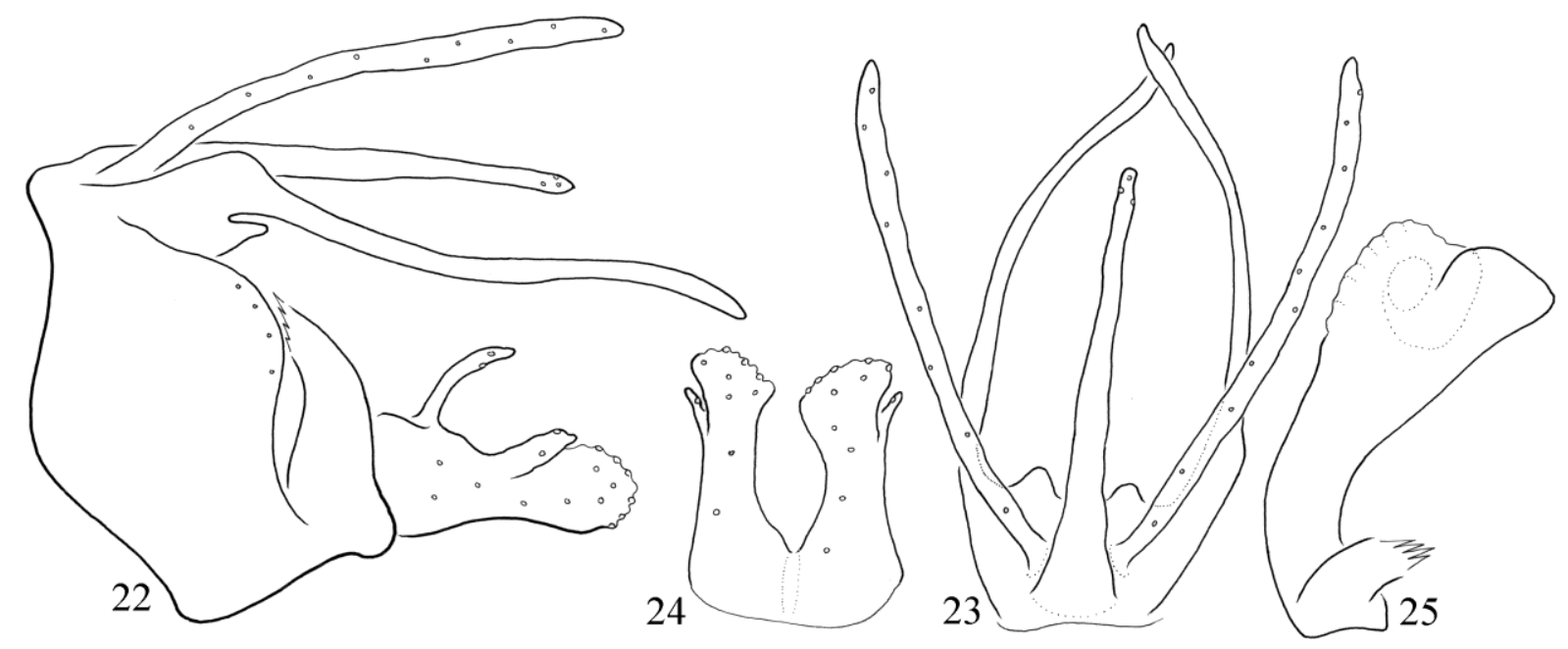

Figures 22-25. Triaenodes fioka sp. nov. Male holotype, $22=$ genitalia in left lateral view, without phallic organ, $23=$ genitalia in dorsal view, 24 = genitalia in ventral view, 25 = phallic organ in left lateral view.

Male genitalia. Segment IX synsclerotized, the subdivided sternum with its posterior partially detached unit giving support to the phallobase by its sclerotized strips. Segment X (upper process of segment X) simple, shorter than cerci. Cerci setose filiform. Paraproct (lower process of segment $\mathrm{X}$ ) forming a pair of long filiform spine-like processes, downward curving. Gonopods with bilobed apex, ventroapical lobe large diverged laterad in ventral view; mesal basodorsal process of the basal plate of gonopods slender, upward directed. Phallic organ forming a downward curving tube with membranous dorsal inflated lobes.

Etymology. fioka from "fióka" nestling in Hungarian, refers to the small ventral process on the paraproctal basement.

\section{Triaenodes fodra sp. nov.}

(Figures 26-29)

Diagnosis. This new species has some similarity to $T$. theiophora complex of the $T$. intricata species group, but differs from all described species by having differently structured paraprocts and gonopods.

Material examined. Holotype. Indonesia, Papua Barat, Birdshead Peninsula, Arfak Mountains,
Demaisi, $1637 \mathrm{~m}, 1^{\circ} 10^{\prime} \mathrm{S}, 133^{\circ} 53^{\prime} \mathrm{E}, 14.02 .2011$, at light PIF expedition (1 male, OPC).

Description. Male (in alcohol). Small, narrow, brown animal. Scape enlarged, 1.2 times longer than head; scent organ covered dorsally with a long flap; pedicel short, third segment long. Maxillary palp fomula IV-I-II-III-V. Spur formula 122. Wing membrane pale yellowish, without any pattern; forewing length $6 \mathrm{~mm}$.

Male genitalia. Segment IX triangular, long ventrad, short dorsad, with suture dividing the sternum and separating the posterior sternal region with the phallobase supporting sclerotized strip. Segment X and paraproct fused, deeply subdivided producing the terminal third directed upward, mesad and laterad. Cerci setose digitiform. Gonopods ending in a slightly narrowing apical lobe in lateral view accompanied by a small finger-like mesal subapical process. Mesal basodorsal process slender curving anterad, dorsad and posterad. Phallic organ with short phallobase and the aedeagus without discernible lateral ridges; phallobase receives a pair of sclerotized strips, these strips are rather detached from the ventroapical region of sternite IX.

Etymology. fodra, from "fodor, bodor" frill, curl in Hungarian, refers to apical region of segment $\mathrm{X}$ with spine-like apices directed upward, mesad and laterad. 

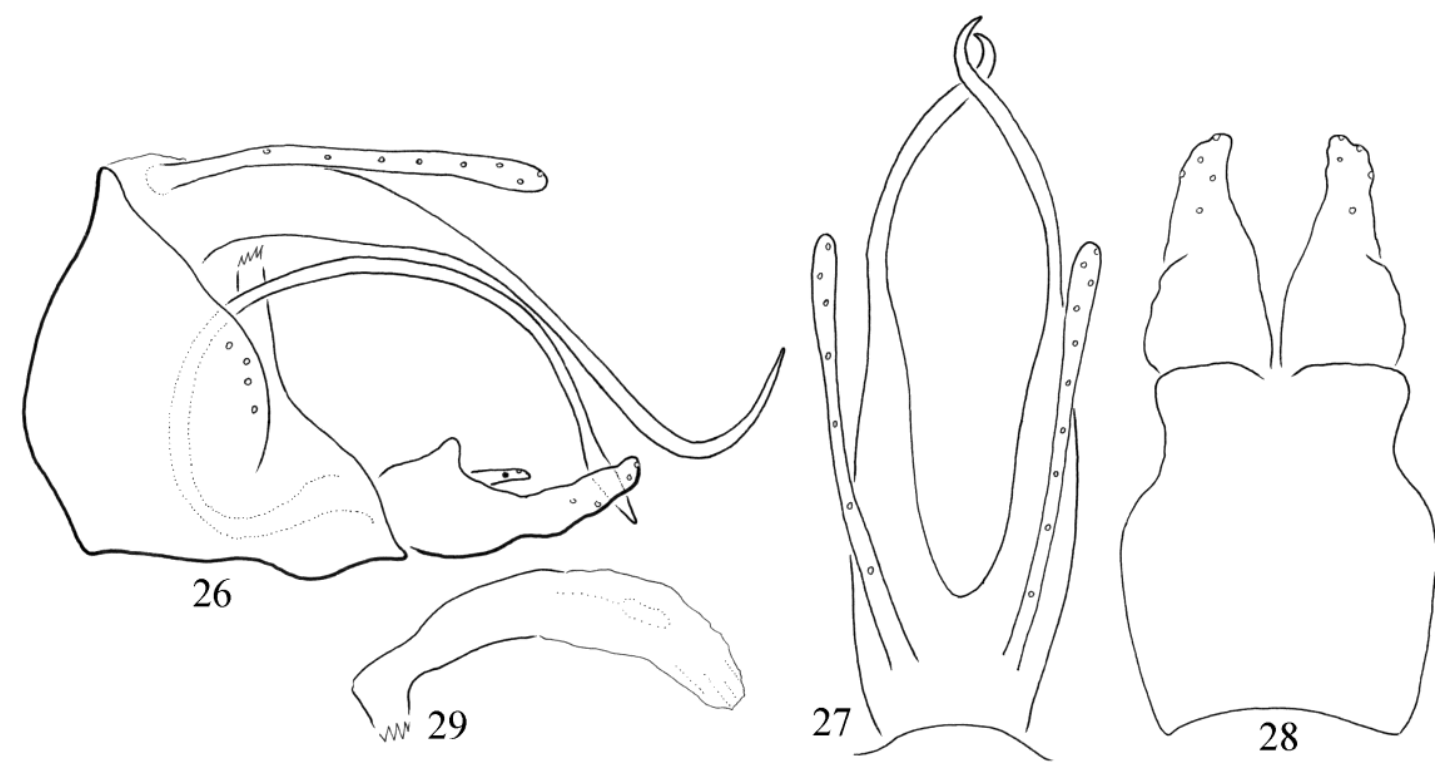

Figures 26-29. Triaenodes fodra sp. nov. Male holotype, $26=$ genitalia in left lateral view, without phallic organ, 27 = genitalia in dorsal view, 28 = genitalia in ventral view, 29 = phallic organ in left lateral view.

Triaenodes fura sp. nov.

(Figures 30-33)

Diagnosis. The strange and unique shape development on the head of segment $X$ and on the apical lobe of gonopods differentiates T. fura sp. nov. from all the known species.

Material examined. Holotype. Solomon Islands, Guadalcanal, Popomanasiu approach, 6800 feet, 5.11.1965, black light, Royal Soc. Exped. B. M. 1966-1, (1 male, NHM).

Description. Male (in alcohol). Brown animal. Scape enlarged, without discernible scent organ; pedicel short, third segment long. Maxillary palp fomula IV-I-II-III-V. Spur formula 1,2,2. Wing membrane pale yellowish, without any pattern; forewing length $7 \mathrm{~mm}$.

Male genitalia. Segment IX synsclerotized, the subdivided sternum with its posterior partially detached unit giving support to the phallobase by its sclerotized strips. Segment X (upper process of segment $\mathrm{X}$ ) with broadened head having variously enlarged humps of alveoli. Cerci setose filiform, slightly shorter than segment X. Paraproct (lower process of segment $\mathrm{X}$ ) fused basally forming a hood over the phallic organ with bifid apex. Api- cal lobe of gonopods vertically directed, armed with elongated alveoli. Mesal basodorsal process of the basal plate of gonopods slender, arching upward and downward posteriad. Phallic organ forming a downward curving and apicad broadening tube with membranous dorsal inflated lobes.

Etymology. fura from "fura" strange in Hungarian refers to the unique shape of the head of segment $X$ as well as of the apical lobe on the gonopods.

\section{Triaenodes gerela sp. nov.}

(Figures 34-36)

Diagnosis. The complex of segment $\mathrm{X}$ and paraproct evolved into a huge javelin operated by a basal shaft through an articulation pivot in combination with the movement of the phallic organ. Javelin complex connected to the phallobase by a highly wrinkled membranous probably flexible tissue regulating the mating movement of the two structures.

Material examined. Holotype. Solomon Islands, Guadalcanal, Popomanasiu approach, 6800 feet, 5.11.1965, black light, Royal Soc. Exped. B. M. 1966-1, (1 male, NHM). 


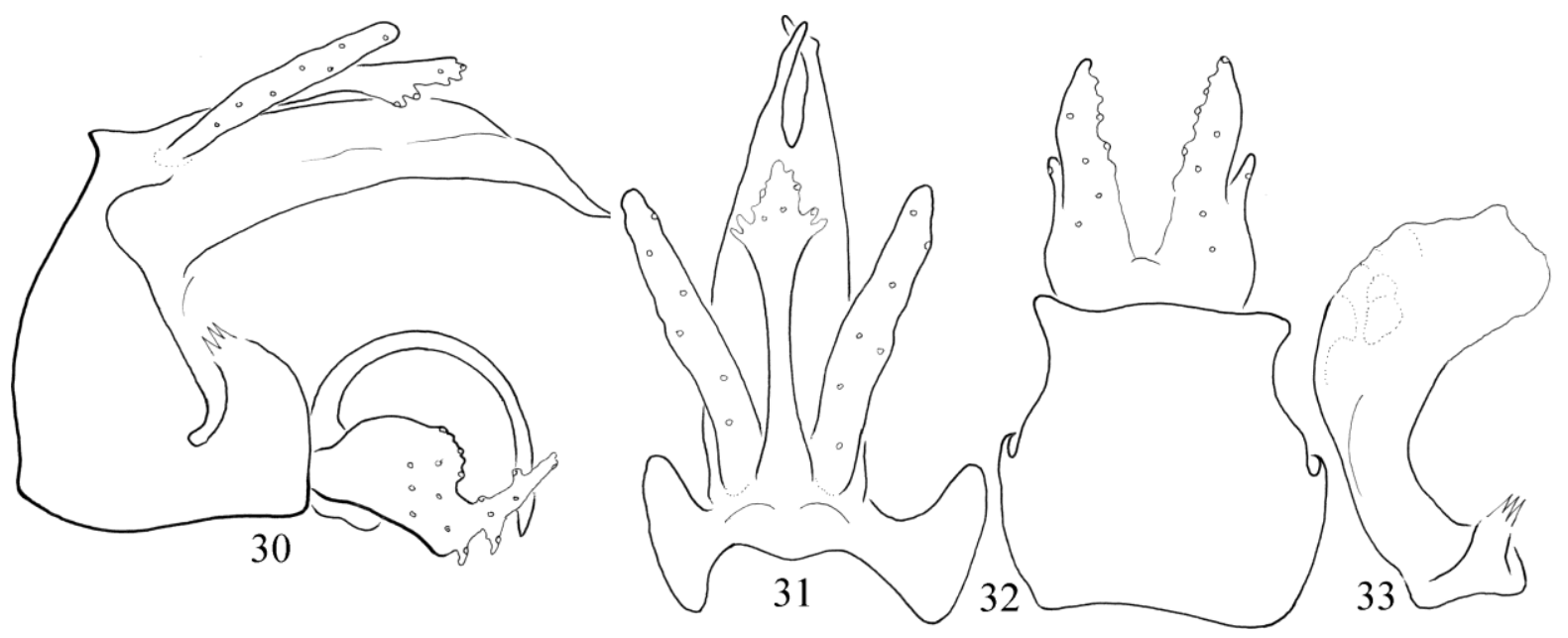

Figures 30-33. Triaenodes fura sp. nov. Male holotype, $30=$ genitalia in left lateral view, without phallic organ, 31 = genitalia in dorsal view, 32 = genitalia in ventral view, 33 = phallic organ in left lateral view.

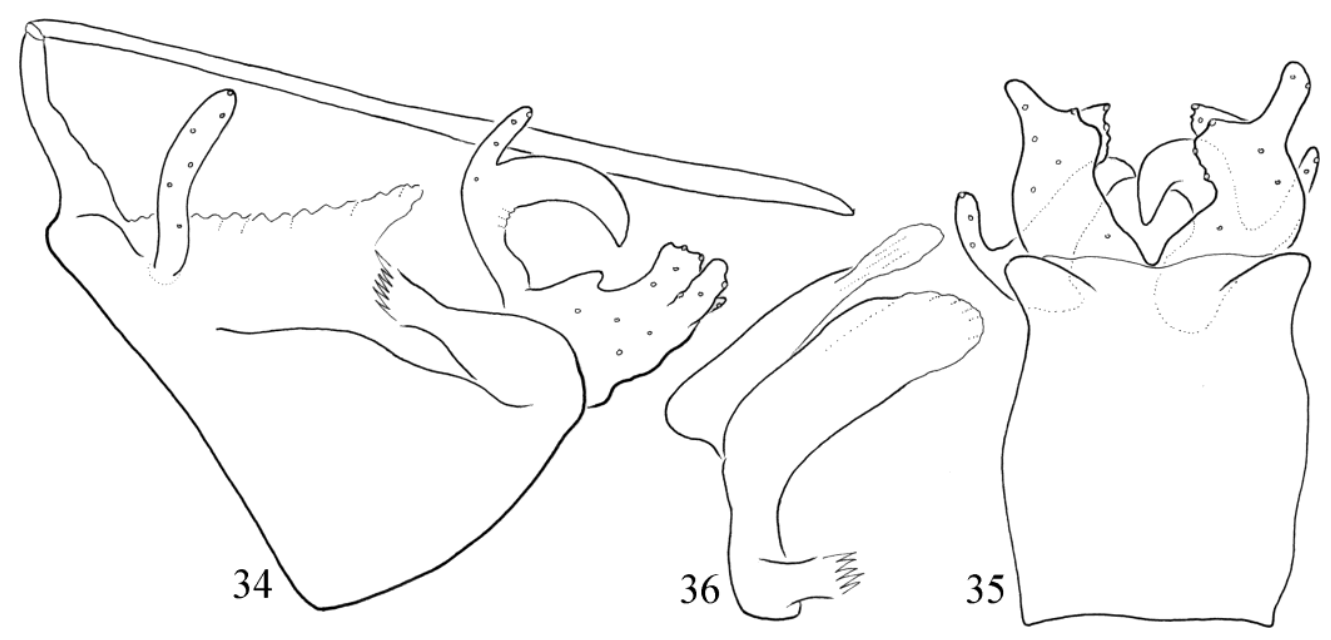

Figures 34-36. Triaenodes gerela sp. nov. Male holotype, $34=$ genitalia in left lateral view, without phallic organ, $35=$ genitalia in ventral view, $36=$ phallic organ in left lateral view.

Description. Male (in alcohol). Brown animal. Scape enlarged, without discernible scent organ; pedicel short, third segment long. Maxillary palp fomula IV-I-II-III-V. Spur formula 1,2,2. Wing membrane pale yellowish, without any pattern; forewing length $6 \mathrm{~mm}$.

Male genitalia. Segment IX synsclerotized, the subdivided sternum with its posterior partially detached unit giving support to the phallobase by its sclerotized strips. Segment X (upper process of segment $X$ ), the basal shaft and the paraproct (lower process of segment $\mathrm{X}$ ), the huge apical long and straight spine fused together by an articulation and forming together a javelin-shaped structure, performing some kind of javelin function during copulation process. Cerci setose short foliform. Apical lobes of gonopods forming a rather complex structure. The pair of mesal basodorsal process of the basal plate of gonopods asymmetrical, but with similar basic structure; the lower arm of the bifid curving process more developed, more sclerotized without setae; the upper arm more slender and setose; right process double sized. Phallic organ forming a downward curving 
and apicad broadening tube with lateral flanges; right lateral flange more produced.

Etymology. gerela from "gerely" javelin in Hungarian refers to the unique structure evolved by the fusion of segment $\mathrm{X}$ and paraproct.

\section{Triaenodes harmasa sp. nov.}

(Figures 37-38)

Diagnosis. This new species having the mesal basodorsal process lobose and sternum IX subdivided belongs to the bernaysae complex of $\mathrm{Ne}$ boiss and Wells, but differs from all the known species by the differently formed periphallic organs.

Material examined. Holotype. Indonesia, Papua Barat, Batanta Island, Northern cost, Warmon stream, 0'50'18.40''S, 130²'41.91'"E, above first waterfall, 21.09.2010, light trap, leg R. Horváth (1 male, OPC). Paratypes. Locality same as of holotype (1 male, OPC). Papua Barat, Batanta Island, Northern cost, Warmon stream, 0'50'23.25's, 130'42'35.18"'E, below second waterfall, 25.10.2010 light trap, leg R. Horváth (4 males, OPC). Papua Barat, Batanta Island, Northern coast, Warmon stream, $0^{\circ} 841^{\prime} 1.52$ ''S, $130^{\circ} 70^{\prime}{ }^{\prime \prime} 10 \mathrm{E}$, above second waterfall, 22.01 . 2013, light trap, leg R. Horváth (1 male, OPC). Papua Barat, Batanta Island, Northern cost, small stream with dry mouth: $0^{\circ} 49^{\prime} 27.84^{\prime}$ 'S, $130^{\circ} 38^{\prime \prime}$ 45.02"E, 1000-1500m above dry mouth, 28.01 . 2012, light trap, leg R. Horváth (7 males, OPC). Papua Barat, Batanta Island, Northern coast, Ron stream, 0'49'16.37' 'S, 130 49'23.72'E, at hut, 8.09.2011, light trap, leg R. Horváth (1 male, OPC). Papua Barat, Batanta Island, Northern coast, small stream, $0^{\circ} 48^{\prime} 47.08^{\prime}$ 'S $130^{\circ} 38^{\prime}$ 18.91"E, 250m from the mouth: 7.09.2011, light trap, leg R. Horváth (1 male, OPC). Papua Barat, Batanta Island, between Arefi and Teluk Warai, valley of ,dried estuary of a stream”, $0^{\circ} 49^{\prime}$ 42.05"S, 130 38'12.23" E, $229 \mathrm{~m}, 27.01 .2014$, at light, leg.T. Kovács, P. Juhász (5 males, OPC). Batanta Island, Welebed, waterwork", valley of Kalijakut River, $0^{\circ} 53^{\prime} 22.85$ 'S, $130^{\circ} 38^{\prime} 25.91$ 'E, 105 m, 23.01.2014, UV light-trap, leg. T. Kovács,
P. Juhász, R. Horváth (2 males, OPC). Papua Barat, Batanta Island, Welebed, valley of Kalijakut River, 0`53'12.88”S, 130 38'16.40”'E, $138 \mathrm{~m}$, 23.01.2014, at light, leg. T. Kovács, P. Juhász, R. Horváth (3 males, OPC). Papua Barat, Batanta Island, valley of Warmon Stream, upper waterfall, 0 50'23.25”S, 130 42'35.18”'E, 150m, 20.01. 2014, at light, leg. T. Kovács, P. Juhász (3 males, OPC). Papua Barat, Batanta Island, valley of Waridor River, 0'51'48.7'S, 130 33'06.3'E, 88 $\mathrm{m}, 31.01 .2014$, at light, leg. T. Kovács, P. Juhász (1 male, OPC). Papua Barat, Batanta Island, right side stream of Forum River, $0^{\circ} 52^{\prime} 22.7$ 'S, $130^{\circ} 27^{\prime} 45.1$ '”, 13.02.2015, at light, T. Kovács, R. Horváth, P. Juhász (5 males, OPC).

Description. Male (in alcohol). Pale animal. Scape little longer than head; scent setae yellow, short, covered with long flap; pairs of strong black scent setal row present on pronotum and smaller on mesonotum; pedicel short with a dorsal digitate elongated process, third segment longer than scape. Maxillary palp fomula I-III-IV-II-V. Spur formula 1,2,2. Wing membrane pale yellowish, without any membrane pattern, but with short and long black alar scent setae; forewing length 6 $\mathrm{mm}$.

Male genitalia. Segment IX comprised of the synsclerotized triangular basal ring and of the subdivided similarly triangular posterior partially detached unit giving support to the phallobase by its sclerotized strips. Segment $X$ is represented by a single mesal long filiform process with slightly dilated apex. Cerci setose filiform, much shorter than segment X. Paraprocts forming a pair of long filiform process. Gonopods subtriangular in lateral view with a pair of apicomesal irregular setose lobe. The mesal basodorsal processes on the basal plate of the gonopods lobose. Phallic organ with short phallobase and the aedeagus with low lateral ridges; phallobase receives a pair of sclerotized strips, these strips arisen from the detached apical portion of sternite IX.

Etymology. harmasa from "hármas" triple in Hungarian refers to the three almost similarly shaped triangular structures composed of the genitalia: the segment IX, the detached posterior part of the subdivided sternum and the gonopode. 


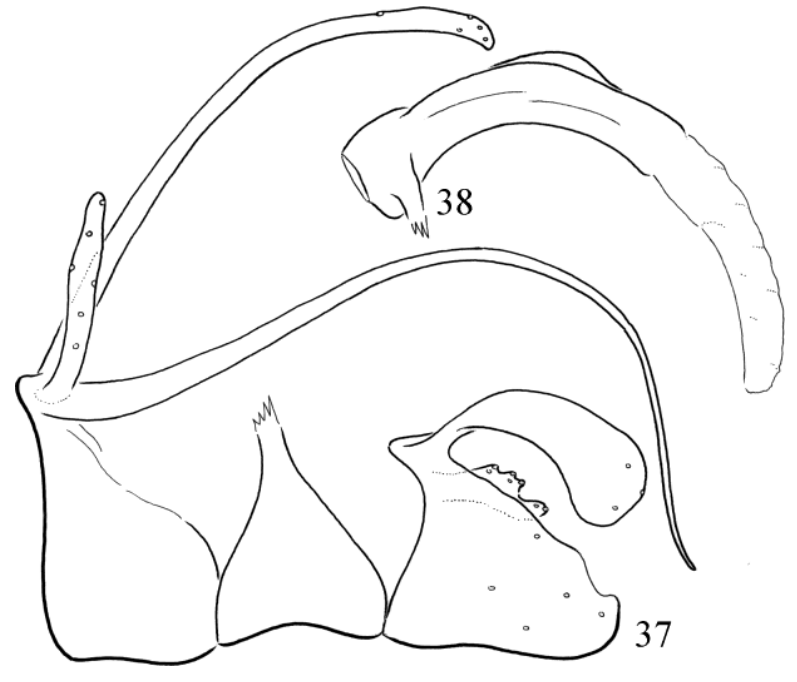

Figures 37-38. Triaenodes harmasa sp. nov. Male holotype, $37=$ genitalia in left lateral view, without phallic organ, $38=$ phallic organ in left lateral view.

\section{Triaenodes hasa sp. nov.}

(Figures 39-42)

Diagnosis. Having the left mesal basodorsal process lost, similar to $T$. telefomicus Kumanski and T. paratlan Oláh \& Mey, but differs from both by having the right mesal basodorsal process dilated and without any subapical process.

Material examined. Holotype. Indonesia, Papua Barat, Birdshead Peninsula, Arfak Mountains, mountain top stream, $2149 \mathrm{~m}, 1^{\circ} 07.620^{\prime} \mathrm{S} 133^{\circ}$ 44.333'E, 19.05.2014, at light, leg. R. Horváth (1 male, OPC).

Description. Male (in alcohol). Brown animal, Scape enlarged, with scent organ of long setae accompanied by a long flap; pedicel short, third segment long. Maxillary palp fomula IV-I-V-IIIII. Spur formula 1,2,2. Wing membrane pale yellowish, without any pattern; forewing length 8 $\mathrm{mm}$.

Male genitalia. Segment IX synsclerotized, subtriangular in lateral view; well-sclerotized frame of sutures encircles the very small tergite IX subdivided into three facets, as visible in dorsal view. Segment $X$ comprising of filiform trifid mesal process (upper process of segment $\mathrm{X}$ ); the median arm of the trifid mesal process shorter than the lateral processes; a pair of short, bare digitate processes present basodorsad. Cerci setose filiform, as long as the lateral processes of segment X. Paraproct (lower process of segment $\mathrm{X}$ ) forming a short subtriangular plate with chalazae basad and setae apicad. Gonopods bilobed apicad; upper lobe digitiform, lower lobe lobate; left mesal basodorsal process lost, right mesal basodorsal process of the basal plate of gonopods curving upward, downward and leftward, highly dilated or bellied one third subbasad. Phallic organ with extremely developed high left ridge; phallobase connected with a pair of lateral sclerotized strips to ventroapical corner of segment IX; this sclerotized strips produced discontinuity in ventrum IX.

Etymology. hasa, from "hasas" bellied in Hungarian, refers to the dilated, bellied submedian section of the mesal basodorsal process arisen from the basal plate of gonopods.

\section{Triaenodes izgaga sp. nov.}

(Figures 43-46)

Diagnosis. The genus Triaenodes has lost the parameres and developed various androconium to replace or substitute paramere function in the sexual selection processes. This new species has a pair of huge parameres on the phallic organ. Similar pair of parameres positioned on the dorsum of the phallic organ has also been found at $T$. costalis Kimmins and T. sinis Malicky. T. izgaga is most similar to $T$. sinis, but differs by having parameres deeply excised and the lateral lobes each bifid, not shallow excised and the lateral lobes pointed; gonopods and the lateral basodorsal processes are differently shaped.

Material examined. Holotype. Indonesia, Papua Barat, Batanta Island, Northern coast, Ron stream, above hut, 0 $49^{\prime} 18.03^{\prime}$ 'S, 130 49' 26.03”E, 15.10.2010, light trap, leg R. Horváth (1 male, OPC). Paratypes. Papua Barat, Batanta Island, Northern coast, Warmon stream, 0 50 ' 18.40' $\mathrm{S}, 130^{\circ} 42^{\prime} 41.91$ ' $\mathrm{E}$, above first waterfall, 21.09.2010, light trap, leg R. Horváth (3 


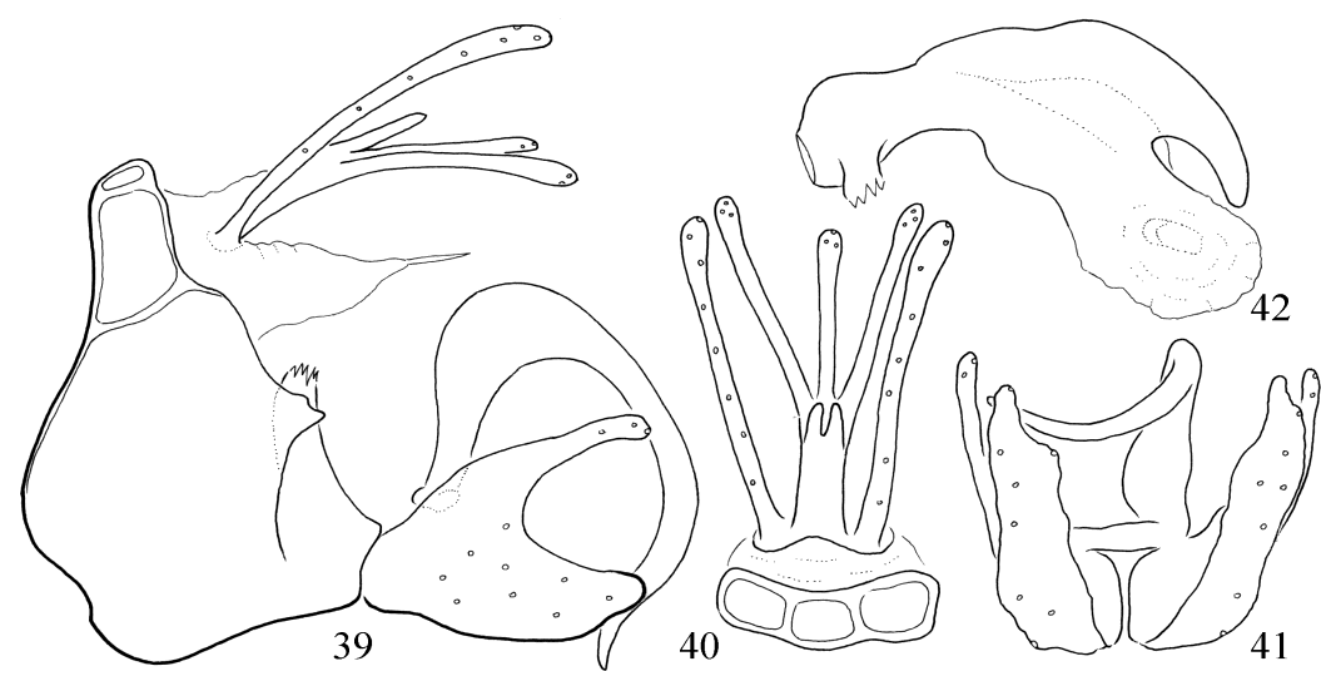

Figures 39-42. Triaenodes hasa sp. nov. Male holotype, $39=$ genitalia in left lateral view, without phallic organ, $40=$ genitalia in dorsal view, 41 = genitalia in ventral view, 42 = phallic organ in left lateral view.

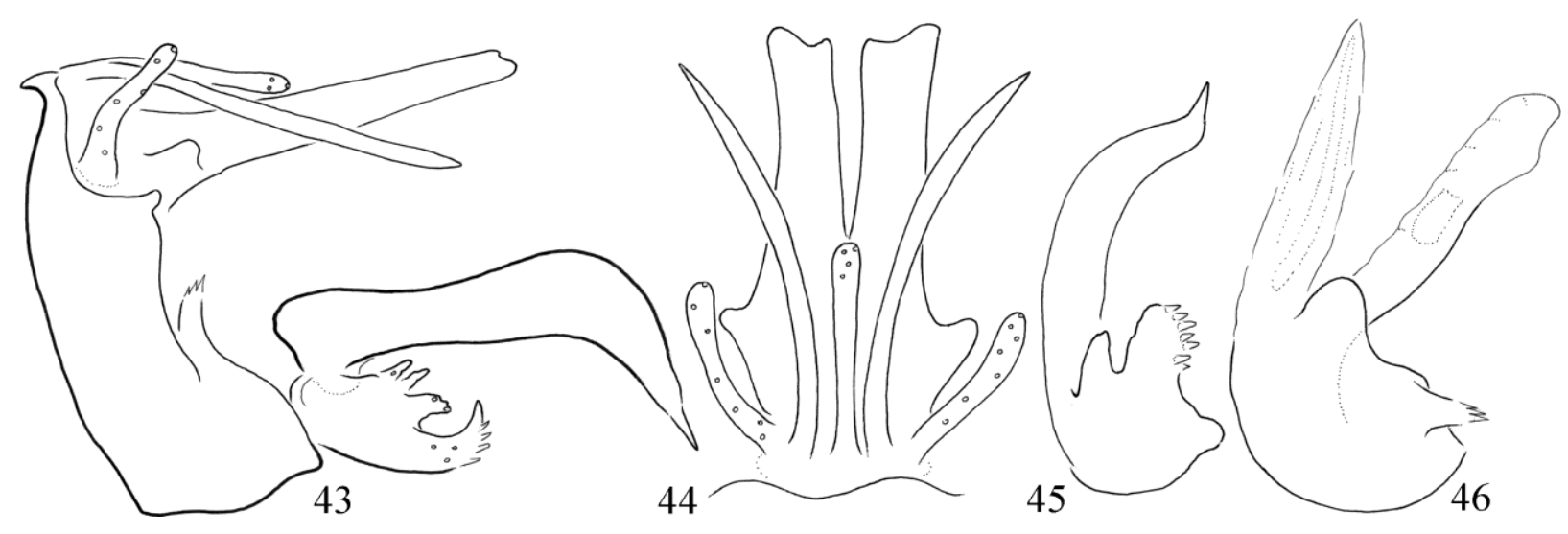

Figures 43-46. Triaenodes izgaga sp. nov. Male holotype, $43=$ genitalia in left lateral view, without phallic organ, $44=$ genitalia in dorsal view, 45 = left gonopod in ventral view, 46 = phallic organ in left lateral view.

males, OPC). Papua Barat, Batanta Island, Northern coast, Warmon stream, 0'50'23.25's, $130^{\circ} 42^{\prime} 35.18^{\prime \prime}$, below second waterfall, 25.10. 2010 light trap, leg R. Horváth (2 males, OPC). Papua Barat, Batanta Island, Northern coast, Warmon stream, 050'29.47" S, 13042'29.16"E above second waterfall, 22.01.2013, light trap, leg R. Horváth (2 male, OPC). Papua Barat, Batanta Island, Northern coast, Warmon stream, $0^{\circ} 50^{\prime}$ 8.52"S, $130^{\circ} 42^{\prime} 50.4^{\prime \prime}$ E, below first waterfall, 22.01.2013, light trap, leg R. Horváth (2 males, OPC). Papua Barat, Batanta Island, Northern coast, Waridor River $0^{\circ} 50^{\prime} 51.04^{\prime \prime} \mathrm{S}, 130^{\circ} 31^{\prime}$
10.85"E under great clearing, 18.01.2013, light trap, leg R. Horváth (1 male, OPC). Papua Barat, Batanta Island, valley of Warmon Stream, upper waterfall, $0^{\circ} 50^{\prime} 23.25^{\prime}$ 'S, $130^{\circ} 42^{\prime} 35.18^{\prime \prime} \mathrm{E}, 150 \mathrm{~m}$, 20.01. 2014, at light, leg. T. Kovács, P. Juhász (14 males, OPC). Papua barat, Batanta Island, valley of Warmon Creck, lower waterfall, $0^{\circ} 50^{\prime} 04.50^{\prime \prime}$, $130^{\circ} 42^{\prime} 54.01$ ' $\mathrm{E}, 37 \mathrm{~m}, 21.01 .2014$, at light leg.T. Kovács, P. Juhász, R. Horváth (3 males, OPC). Papua Barat, Batanta Island, valley of Waridor River, 0 ${ }^{\circ} 51^{\prime} 48.7$ 'S, 130 33'06.3'E, 88m, 31.01. 2014, at light, leg. T. Kovács, P. Juhász (1 male, OPC). 
Description. Male (in alcohol). Medium-sized, brown animal. Scape enlarged, with scent organ covered with a long flap; brown short setae comprised of androconia; pedicel bears similar short brown setae of androconia; third antennal segment long. Black and long setae of androconia present as long tuft on the basal region of costal vain and on the tegula. Maxillary palp fomula IV-I-II(II,III,V). Spur formula 1,2,2. Wing membrane pale yellowish, without pronounced pattern; forewing length $9 \mathrm{~mm}$.

Male genitalia. Segment IX fused and short, without any discernible suture or groove; posterior region of sternum IX giving a sclerotized strip to support phallobase. Segment X composed of a shorter digitiform setose mesal process and a pair of spine-like lateral process down and laterad directed. Paraproct evolved into a large plate over the phallic organ with basolateral humps and deeply divided bifid lateral lobes. Cerci setose digitiform, shorter than segment X. Gonopods with upward curving apex and one larger and two smaller digitiform dorsal process; huge spine-like lateral basodorsal process curving downward and mesad. Middle located phallic organ with enlarged phallobase; a unique pair of large paramere striated with a discernible internal spine-like structure; phallobase receives a pair of sclerotized strips, this strip detached from the ventroapical region of sternite IX.

Etymology. izgaga, from "izgága" twitchy, restless in Hungarian, refers to the various brown antennal and black alar androconia evolved in sexual selection, as well as the presence in a highly produced form of the titillating parameres.

\section{Triaenodes jobba sp. nov.}

(Figures 47-48)

Diagnosis. Having the left mesal basodorsal process lacking and the right process present, this new species is a sibling of the species T. bala sp. nov., T. hasa sp. nov., T. paratlan Oláh \& Mey, and T. telefomicus Kumanski. The position of the dilation on the mesal basodorsal process distinguishes these siblings.
Material examined. Holotype. Indonesia, $\mathrm{Pa}-$ pua Barat, Batanta Island, Northern coast, Waridor River $0^{\circ} 52^{\prime} 6.24 " \mathrm{~S}, 130^{\circ} 31^{\prime} 30.58 \mathrm{E} \mathrm{E}, 18.01$. 2013, light trap, leg R. Horváth (1 male, OPC).

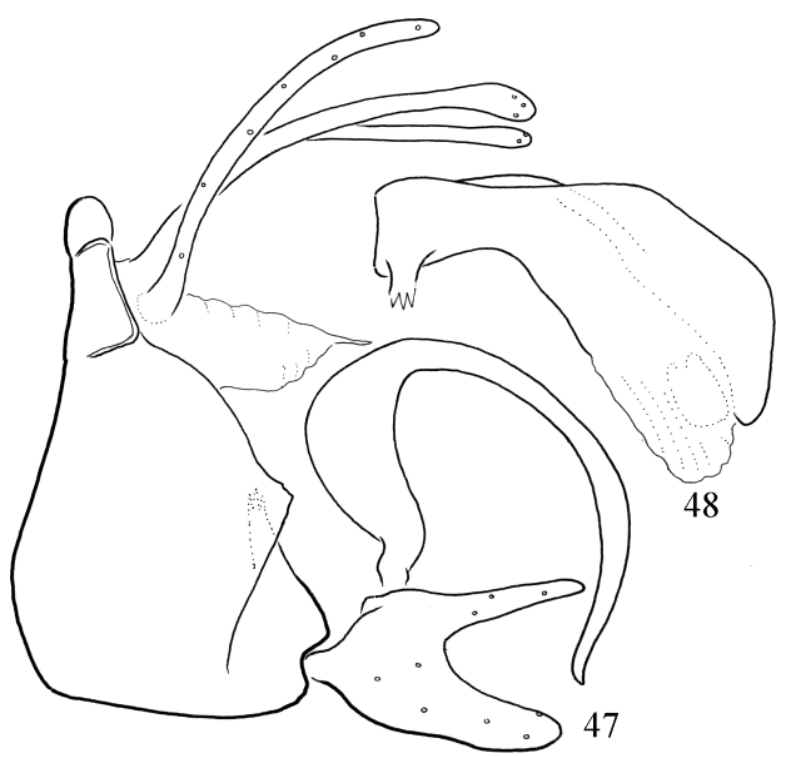

Figures 47-48. Triaenodes jobba sp. nov. Male holotype, 37 = genitalia in left lateral view, without phallic organ, $38=$ phallic organ in left lateral view.

Description. Male (in alcohol). Brown animal, Scape enlarged, with scent organ of long black setae accompanied by a long flap; pedicel short, third segment long. Maxillary palp fomula IV-III-III-V. Spur formula 1,2,2. Wing membrane pale yellowish, without any pattern; forewing length 7 $\mathrm{mm}$.

Male genitalia. Segment IX synsclerotized, subtriangular in lateral view; well-sclerotized frame of sutures encircles the very small tergite IX subdivided into three facets, as visible in dorsal view. Segment $X$ comprising of filiform trifid mesal process (upper process of segment $\mathrm{X}$ ); the median arm of the trifid mesal process as long as the lateral processes; lateral processes with mesad turning capitate apex, a pair of short, bare digitate processes lacking or indistinct basodorsad. Cerci setose filiform, as long as the lateral processes of segment X. Paraproct (lower process of segment $\mathrm{X})$ forming a short subtriangular plate with chalazae basad and setae apicad. Gonopods bilobed 
apicad; upper lobe digitiform, lower lobe lobate; left mesal basodorsal process lost, right mesal basodorsal process of the basal plate of gonopods curving upward, downward and leftward, dilated or bellied one third basad. Phallic organ with extremely developed high left ridge; phallobase connected with a pair of lateral sclerotized strips to ventroapical corner of segment IX; this sclerotized strips produced discontinuity in ventrum IX.

Etymology. jobba from "jobb" right in Hungarian refers to the right mesal basodorsal process of the basal plate on the gonopods present.

\section{Triaenodes kalija sp. nov.}

(Figures 49-52)

Diagnosis. The basic architecture of the genitalia is similar to T. marleorum sp. nov., T. sarla sp. nov., T. tafana Kimmins, T. thespios Malicky T. torpa sp. nov., but differs by having paraproct with lateral lobes; by different lateral profile of the gonopods; paramere lacking similarly to $T$. sarla sp. nov.

Material examined. Holotype. Indonesia, Papua Barat, Batanta Island, Welebed, "waterwork", valley of Kalijakut River, $0^{\circ} 53^{\prime} 22.85$ ”S, $130^{\circ}$
38'25.91'E, 105m, 23.01.2014, UV light-trap, leg. T. Kovács, P. Juhász, R. Horváth (1 male, OPC). Paratypes. Papua Barat, Batanta Island, Welebed, valley of Kalijakut River, $0^{\circ} 53$ ' 12.88”S, 130³8'16.40”'E, 138m, 23.01. 2014, at light, leg. T. Kovács, P. Juhász, R. Horváth (5 males, 1 female; OPC). Papua Barat, Batanta Island, Kalijakut River, $0^{\circ} 52^{\prime} 49.1$ 'S, $130^{\circ} 38^{\prime} 4.9^{\prime \prime} \mathrm{E}$, 16.02.2015, UV light-trap, leg. T. Kovács, P. Juhász, (12 males, 2 females; OPC). Papua Barat, Batanta Island, Kalijakut River, $0^{\circ} 52^{\prime} 52.0^{\prime \prime} \mathrm{S}$, $130^{\circ} 38^{\prime} 8.0^{\prime \prime} \mathrm{E}, 16.02 .2015$, at light, leg. T. Kovács, $\mathrm{P}$. Juhász (2 males, OPC).

Description. Male (in alcohol). Small, brown animal. Scape enlarged, without discernible scent organ and covering flap; pedicel short, third segment long. Maxillary palp fomula IV-I(II,III,V). Spur formula 1,2,2. Wing membrane pale yellowish, hyaline window present on lower anastomosis; forewing length $7 \mathrm{~mm}$.

Male genitalia. Segment IX fused with triangular sternum and short tergum, without any discernible suture or groove. Segment X simplified into a single gradually tapering median process with few tiny emerged setae. Paraproct forming a broad based plate hooding the phallic organ, constricted subapicad and produced apicolateral lobes.

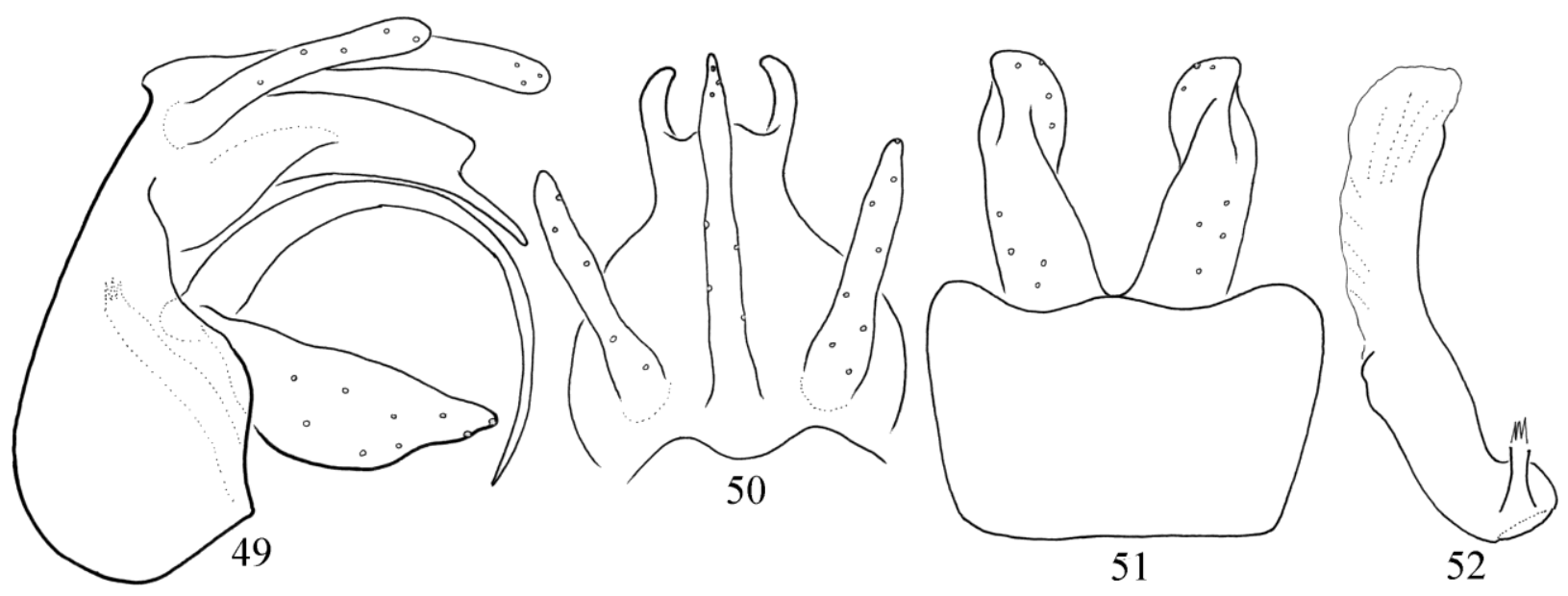

Figures 49-52. Triaenodes kalija sp. nov. Male holotype, $49=$ genitalia in left lateral view, without phallic organ, $50=$ genitalia in dorsal view, 51 = genitalia in ventral view, 52 = phallic organ in left lateral view. 
Cerci setose digitiform, shorter than segment X. Gonopods subtriangular in lateral view; spine-like lateral basodorsal process curving. Middle located phallic organ more sclerotized ventrad; phallobase receives a pair of sclerotized strips from the ventroapical region of segment IX.

\section{Etymology. Named for the type locality.}

\section{Triaenodes ketaga sp. nov.}

(Figures 53-56)

Diagnosis. Most close to T. manni Banks, 1936 described from Viti Levu, but differs by having cerci shorter than segment $\mathrm{X}$, while cerci longer than segment $\mathrm{X}$ at T. manni; segment $\mathrm{X}$ broadly bifid, not simple; gonopods subquadrangular in lateral view, not with triangular apical margin and not constricted middle, mesal basodorsal process short and robust, not slender.

Material examined. Holotype. Fiji Islands, Viti Levu, Forestry Area, $10 \mathrm{~m}$, Inland from Galoa, 31.08.1975, M.V. light, leg. P.A. Maddison (1 male, FVI4255, NHM).

Description. Male (in alcohol). Brown animal. Scape enlarged, without discernible scent organ, pedicel short, third segment long. Maxillary palp fomula IV-I-II-III-V. Spur formula 1,2,2. Wing membrane pale yellowish, without any pattern; forewing length $6 \mathrm{~mm}$.

Male genitalia. Segment IX synsclerotized, the subdivided sternum with its posterior partially detached unit giving support to the phallobase by its sclerotized strips. Segment $X$ (upper process of segment $\mathrm{X}$ ) comprising of filiform bifid mesal process; bifid apex broadening. Cerci setose filiform, shorter than segment X. Paraproct (lower process of segment $\mathrm{X}$ ) forming a pair of long filiform spine-like processes, downward curving on its apical third. Gonopods subquadrangular in lateral view; small dorsal subapical lobe present; mesal basodorsal process of the basal plate of gonopods short capitate. Phallic organ forming a downward curving tube with membranous apex.

Etymolog. ketaga from "kétagú" two-armed in Hungarian refers to bifid apex of segment X.
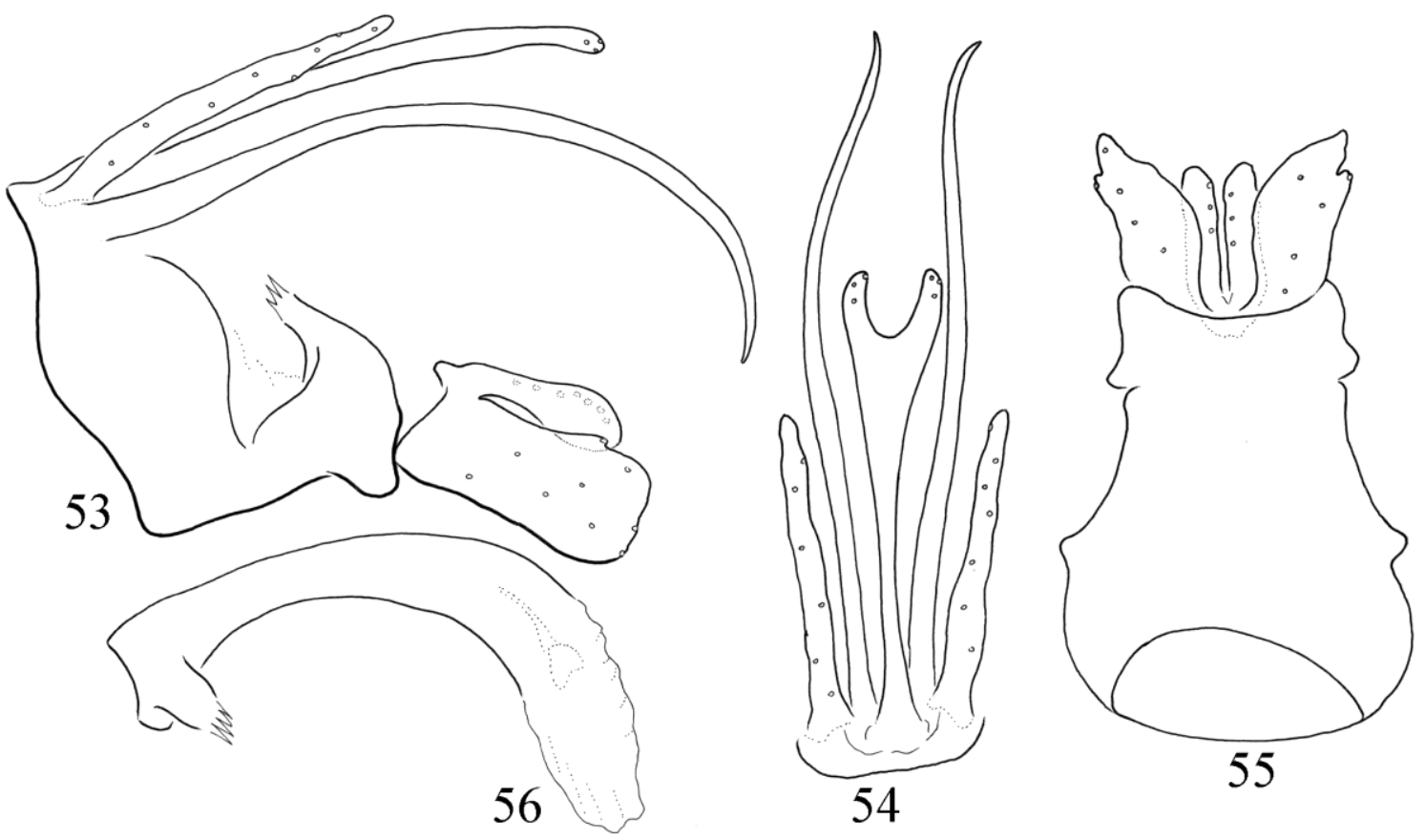

Figures 53-56. Triaenodes ketaga sp. nov. Male holotype, 53=genitalia in left lateral view, without phallic organ, 54=genitalia in dorsal view, 55=genitalia in ventral view. 56=phallic organ in left lateral view. 


\section{Triaenodes koba sp. nov.}

(Figures 57-60)

Diagnosis. Most close to T. bunka sp. nov., but differs by having segment $X$ with short capitate apex; pair of paraproct spines asymmetrical; gonopods with ventroapical lobe rounded, not truncate; mesal basodorsal process differently shaped; membranous endotheca more elaborated, especially on dorsum.

Material examined. Holotype. Fiji Islands, Vanua Levu, Savudvodro Dam, 10.02.1971, leg. G.S. Robinson (1 male, NHM).

Description. Male (in alcohol). Brown animal, Scape enlarged, without discernible scent organ; pedicel short, third segment long. Maxillary palp fomula IV-I-II-III-V. Spur formula 1,2,2. Wing membrane pale yellowish, without any pattern; forewing length $8 \mathrm{~mm}$.

Male genitalia. Segment IX synsclerotized, the subdivided sternum with its posterior partially detached unit giving support to the phallobase by its sclerotized strips. Segment X (upper process of segment X) filiform with wrinkled apex. Cerci setose filiform, little shorter than segment $\mathrm{X}$.
Paraproct (lower process of segment X) forming a pair of long filiform asymmetric spine-like processes, left process half as developed and long as the right side process. The single asymmetric spine like sclerotized pointed process attached to paraproct basement is more developed as long as the right-side paraproctal process. Gonopods bilobed, ventral lobe enlarged; mesal basodorsal process of the basal plate of gonopods ventrally flat and very broad. Phallic organ forming a downward arching tube with membranous apex and dorsum.

Etymology. koba from "kobak" head in Hungarian, refers to the short capitate apex of segment $X$.

\section{Triaenodes lemeza sp. nov.}

(Figures 61-64)

Diagnosis. This small new species has resemblance to the $T$. doryphora complex of the T. intricata species group established by Neboiss \& Wells (1998), especially to T. empheira, but differs by having paraproct fused, not paired as well as the gonopods and the mesal basodorsal process differently formed.

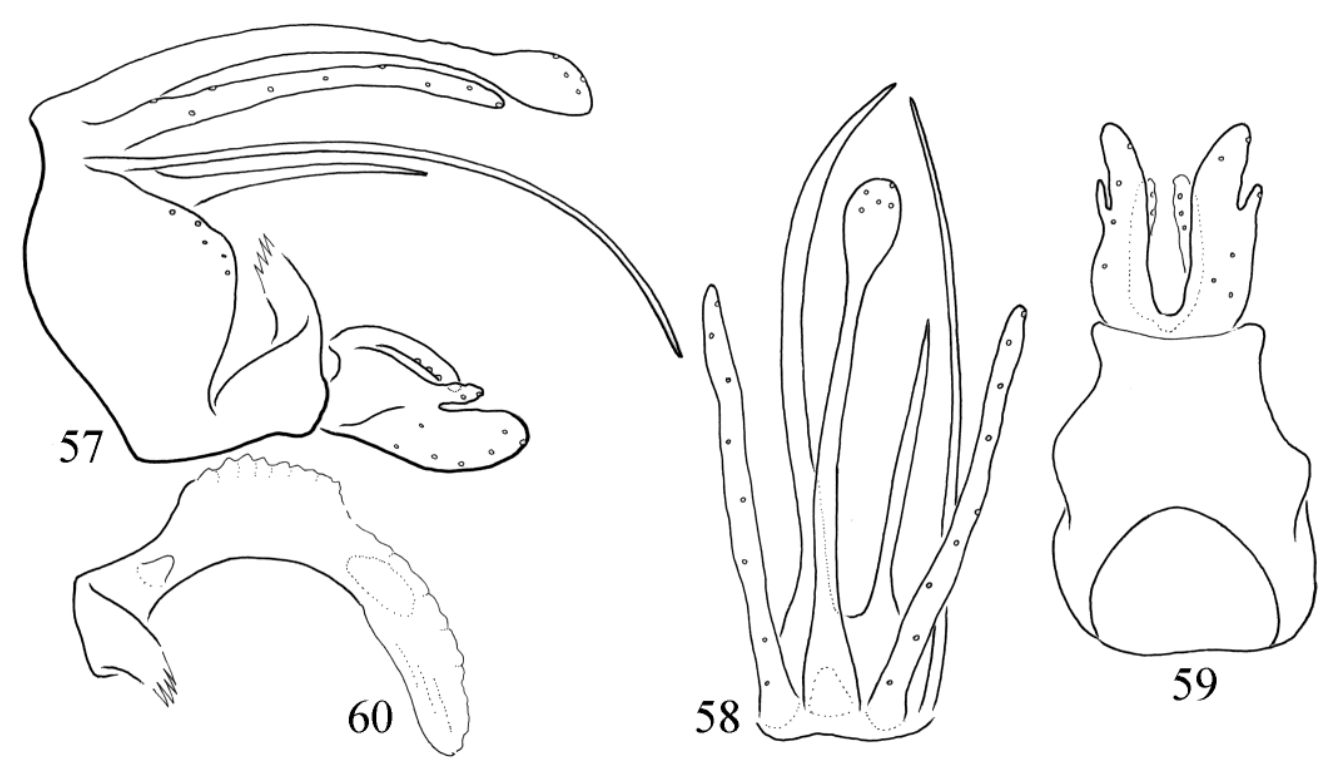

Figures 57-60. Triaenodes koba sp. nov. Male holotype, 57 = genitalia in left lateral view, without phallic organ, $58=$ genitalia in dorsal view, 59 = genitalia in ventral view, 60 = phallic organ in left lateral view. 
Material examined. Holotype. Indonesia, Papua Barat, Birdshead Peninsula, Snow Mountains, Baliem Resort, $1947 \mathrm{~m}, 20 \mathrm{~km}$ from Wamena, $4^{\circ} 03.578^{\prime} \mathrm{S} 139^{\circ} 01.747^{\prime} \mathrm{E}, 23-28$. 05. 2014, at light, leg. R. Horvath (1 male, OPC). Paratype. Locality same as of holotype (1 male, OPC).

Description. Male (in alcohol). Pale animal. Scape short as long as head; scent setae yellow short with upward curving apical third; pedicel short, third segment as long as scape. Maxillary palp fomula I-IV-(II,III)-V. Spur formula 1,2,2. Wing membrane pale yellowish, without any pattern; forewing length $5 \mathrm{~mm}$.

Male genitalia. Segment IX comprised of the synsclerotized basal ring and the subdivided sternum with its posterior partially detached unit giving support to the phallobase by its sclerotized strips. Segment $X$ is represented by a single mesal long filiform process with slightly dilated apex. Cerci setose filiform, shorter than segment X. Paraprocts fused, not paired and composed of the short, less sclerotized pointed structure below segment $X$ and of a single heavily sclerotized spine-like long downward curving process. Gonopods subtriangular in lateral view with a tapering apicoventral lobe bearing only a few apical setae and with an apicomesal lobe fully packed with short and strong setae on its mesal surface. The mesal basodorsal processes on the basal plate of the gonopods composed of a sickle-shaped broad digitiform spine-like process and a vertical laminar plate pointed apicad. Phallic organ with short phallobase and the aedeagus with low lateral ridges; phallobase receives a pair of sclerotized strips, these strips arisen from the rather detached apical portion of sternite IX.

Etymolog. lemeza from "lemezes" laminar in Hungarian, refers to the platiform (plate-shaped), laminar additional structure combined with the mesal basodorsal process on the basal plate of gonopods.

\section{Triaenodes marleorum sp. nov.}

(Figures 65-68)

Diagnosis. Having a single paramere below the aedeagus this new species is similar to $T$. tafana Kimmins, T. thespios Malicky and T. torpa sp. nov., but differs from them by having paraproct almost truncate, only slightly excised apicad in dorsal view, lateral profile of gonopods different; lateral basoventral region of paraproct similar to T. torpa sp. nov. with very elaborated pattern of lobes and fingers, partially present at $T$. tafana, completely lacking at $T$. thespios, at least not recorded and not drawn. These four species form a rather similar complex with the presence of spine-shaped single paramere.

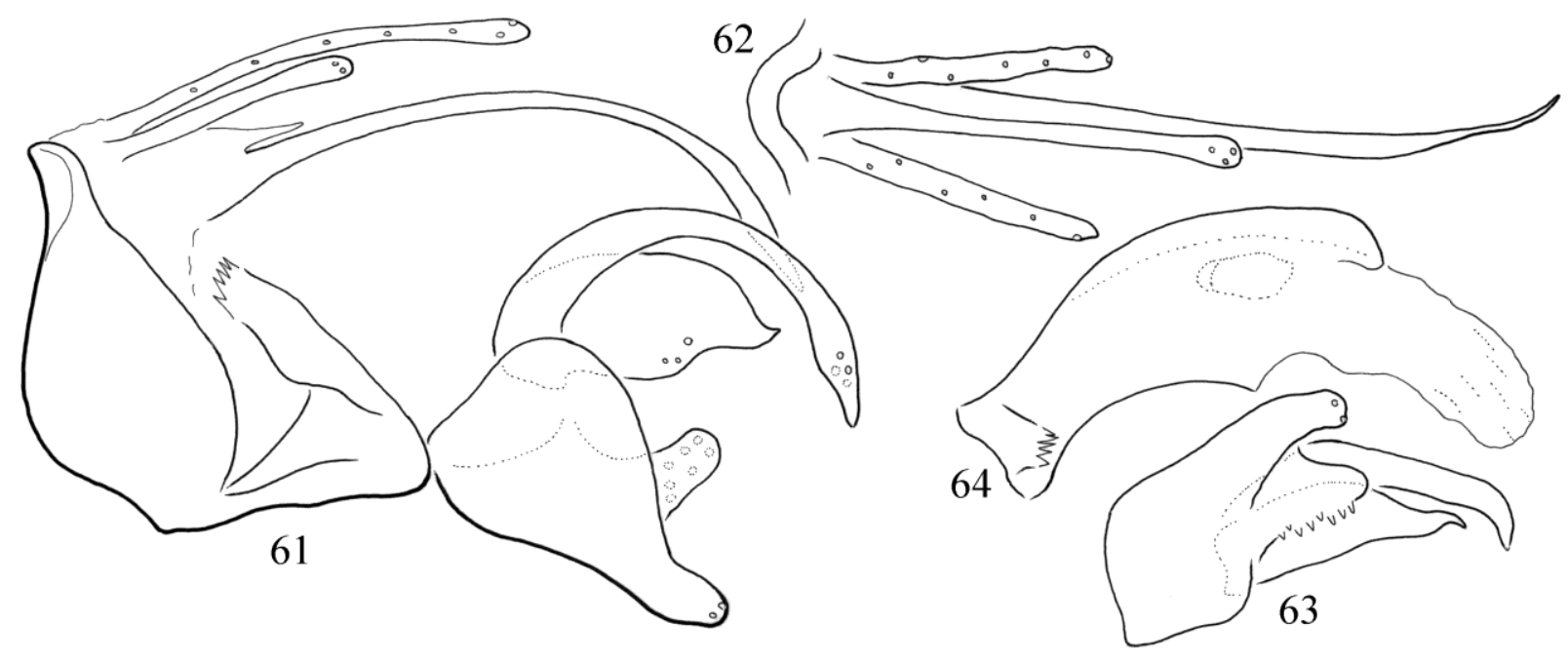

Figures 61-64. Triaenodes lemeza sp. nov. Male holotype, $61=$ genitalia in left lateral view, without phallic organ, 62 = genitalia in dorsal view, 63 = left gonopod in ventral view, 64 = phallic organ in left lateral view. 
Material examined. Holotype. Indonesia, Papua Barat, Batanta Island, Northern coast, Waridor River, $0^{\circ} 50^{\prime} 37.43 " \mathrm{~S}, \quad 130^{\circ} 31 ' 28.45^{\prime \prime} \mathrm{E}$ shippable endpoint, 9.09.2011, light trap, leg R. Horváth (1 male, OPC). Paratype. Papua Barat, Batanta Island, Kalijakut River, 0`52'52.0”, $130^{\circ} 38^{\prime} 8.0$ ', 16.02.2015, at light, leg. T. Kovács, P. Juhász (1 male, OPC).

Description. Male (in alcohol). Small, brown animal. Scape slightly enlarged, without dispensable scent organ; pedicel short, third segment long. Maxillary palp fomula IV-I-II-III-V. Spur formula 1,2,2. Wing membrane pale yellowish, without any hyaline window; forewing length 4 $\mathrm{mm}$.

Male genitalia. Segment IX fused with traingular sternum and short tergum, tergum visible as a more sclerotized vertical band. Segment X simplified into a single filiform median process with a few tiny emerged setae. Paraproct composed of a horizontal plate broadening laterad on basal half and hooding the phallic organ, a pair of lateral lobe with very slender filiform process. Cerci setose digitiform, shorter than segment X. Gonopods with upward curving apex and a small budding dorsal process middle; spine-like lateral basodorsal curving process. Middle located phallic organ asymmetric with more developed left lateral ridge; a unique single, well developed black spine-like paramere present; phallobase receives a pair of sclerotized strips, this strip runs on the apical margin of sternite IX as a more pigmented darker band.

Etymology. This species is dedicated to Rodolfo Giusti de Marle and Iskandar F. Giusti de Marle, staff members of the Papua Paradise EcoResort (Birie Island). They have participated in caddisfly collection on Batanta Island.

\section{Triaenodes nakla sp. nov.}

(Figures 69-72)

Diagnosis. Most close to T. fioka sp. nov., but differs by having left arm of paraproct modified with apical third downward and mesad turning; paraproct basement without ventral process; apical margin of gonopods rounded in ventral view, not diverged laterad; mesal basodorsal process robust, not slender.

Material examined. Holotype. New Hebrides, Ridge E of South Bay, Malekula 1300 feet, 12.10. 1971, leg. G. S. Robinson, Royal Soc. New Hebrides, 1971 (1 male, NHM). Paratype. New Hebrides, Santo, Mt Tabwemasana 4500 feet, 2. 09.1971, leg. G. S. Robinson, Royal Soc. New Hebrides, 1971 (1 male, OPC).

Description. Male (in alcohol). Brown animal. Scape enlarged, without discernible scent organ; pedicel short, third segment long. Maxillary palp formula IV-I-II-III-V. Spur formula 1,2,2.
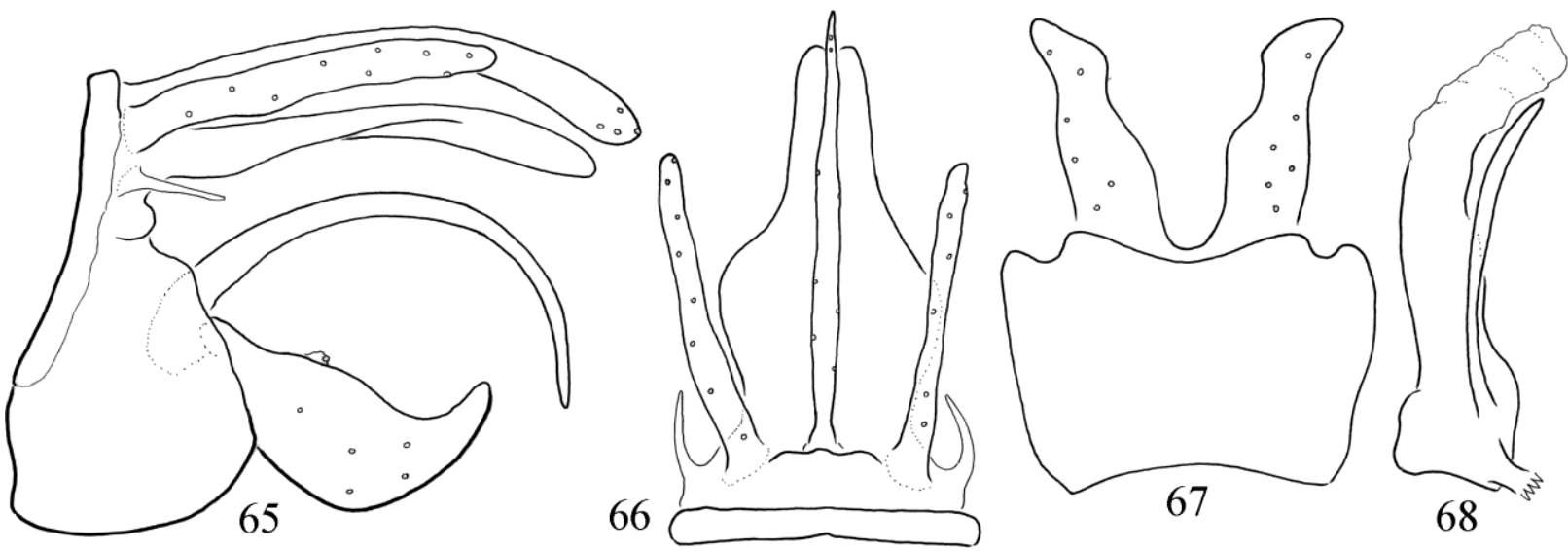

Figures 65-68. Triaenodes marleorum sp. nov. Male holotype, $65=$ genitalia in left lateral view, without phallic organ, $66=$ genitalia in dorsal view, 67 = genitalia in ventral view, $68=$ phallic organ in left lateral view. 
Wing membrane pale yellowish, without any pattern; forewing length $8 \mathrm{~mm}$.

Male genitalia. Segment IX synsclerotized, the subdivided sternum with its posterior partially detached unit giving support to the phallobase by its sclerotized strips. Segment X (upper process of segment X) simple, shorter than cerci. Cerci setose filiform. Paraproct (lower process of segment $\mathrm{X}$ ) forming a pair of long filiform spine-like processes, downward curving; left arm deformed: downward turning shallow C-shaped in lateral view and mesad directed shallow S-shaped in dorsal view. Gonopods with bilobed apex, ventroapical lobe large rounded, dorsal lobe small; mesal basodorsal process of the basal plate of gonopods short upward directed. Phallic organ forming a downward curving tube with membranous dorsal inflated lobes.

Etymology. nakla from "nyakla" a kind of collapse or crumple in Hungarian refers to the deformed shape of the left arm of the spine-like paraproct.

\section{Triaenodes nemaproka sp. nov.}

(Figures 73-74)

Diagnosis. The basic architecture of the genitalia, and particularly the dorsum of segment IX with suture separated tergum, is similar to $T$. aproka sp. nov., T. bala sp. nov., T. hasa sp. nov., $T$. jobba sp. nov., $T$. paratlan Oláh \& Mey, and $T$. telefomicus Kumanski. However, the left mesal basodorsal process is present not lost. Together with $T$. aproka this new species is probably the ancestral species of the lineage. Most close to $T$. aproka sp. nov., but differs by having tergum IX less framed by sutures; by segment $X$ shorter with triangular apex, not with capitate apex; by differently shaped mesal basodorsal processes and gonopods.

Material examined. Holotype. Indonesia, Papua Barat, Batanta Island, Teluk Warai, stream, $0^{\circ} 50^{\prime} 51.0^{\prime \prime} \mathrm{S}, 130^{\circ} 35^{\prime} 14,0^{\prime \prime} \mathrm{E}, 11.02 .2015$, at light, leg. T. Kovács, P. Juhász (1 male, OPC). Paratypes. Locality same as of holotype (1 male, OPC). Papua Barat, Batanta Island, Kalijakut River, $0^{\circ} 52$ '49.1'S, $130^{\circ} 38^{\prime} 4.9^{\prime \prime E}, 16.02 .2015$, UV light-trap, leg. T. Kovács, P. Juhász, (1 male, OPC).

Description. Male (in alcohol). Brown animal, Scape slightly enlarged, with discernible scent organ present as a darker flap-covered area; pedicel short, third segment long. Maxillary palp formula IV-I-III-II-V. Spur formula 1,2,2. Wing membrane pale yellowish, without any pattern and without any scent setae; forewing length 7 $\mathrm{mm}$.

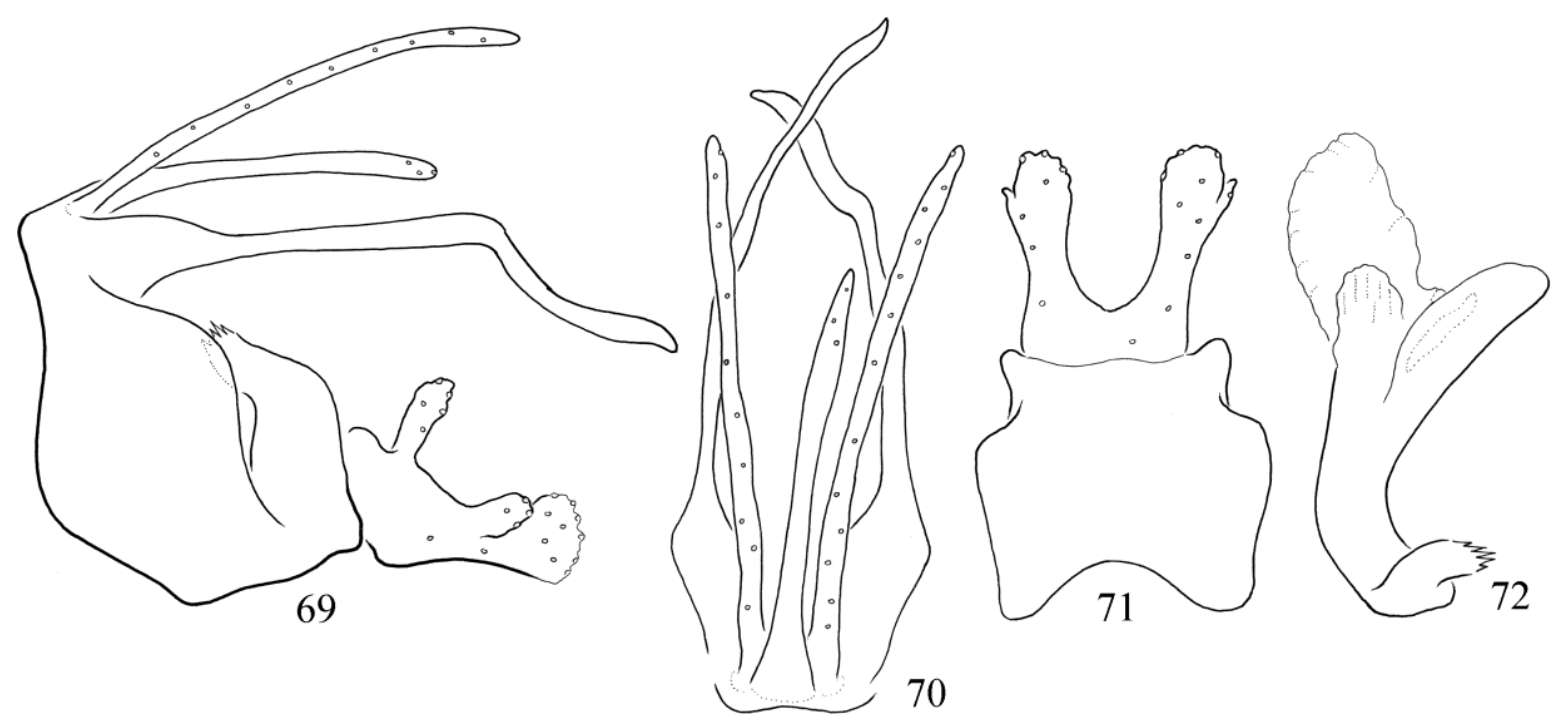

Figures 69-72. Triaenodes nakla sp. nov. Male holotype, $69=$ genitalia in left lateral view, without phallic organ, $70=$ genitalia in dorsal view, 71 = genitalia in ventral view, $72=$ phallic organ in left lateral view. 
Male genitalia. Segment IX synsclerotized, subtriangular in lateral view; sclerotized frame of sutures encircles the very small tergite IX incomeplete. Anterior suture lacking. Segment X comprising of digitiform mesal process (upper process of segment $\mathrm{X}$ ) with triangular apex. Cerci setose filiform, two-thirds long of segment X. Paraproct (lower process of segment $\mathrm{X}$ ) forming a less sclerotized long mesal process. Gonopods bilobed apicad; upper lobe long arching digitiform, lower lobe shorter; a pair of mesal basodorsal process present curving upward and downward. Phallic organ with dilated membranous apical portion of the aedeagus; phallobase connected with a pair of lateral sclerotized strips to sclerotized strips produced discontinuity in ventrum IX.

Etymology. nemaproka, from "nem apróka" not tiny in Hungarian, refers to similarity, but a recent contemporary divergence from $T$. aproka sp. nov.

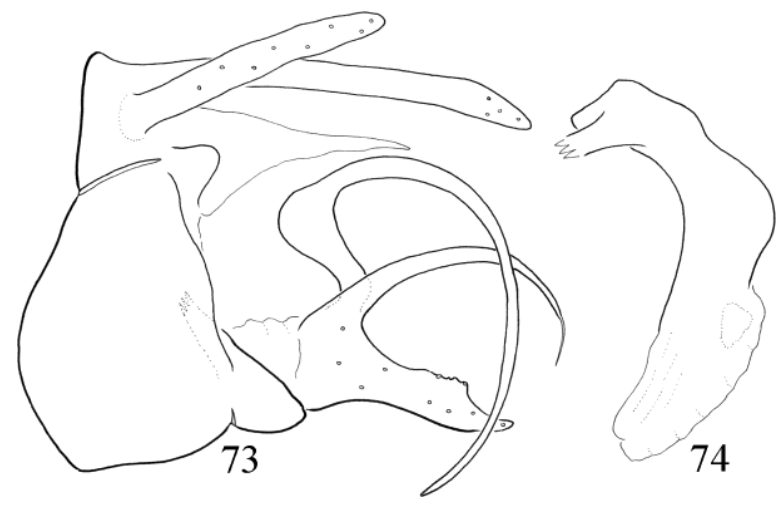

Figures 73-74. Triaenodes nemapraka sp. nov. Male holotype, 73 = genitalia in left lateral view, without phallic organ, $74=$ phallic organ in left lateral view.

Triaenodes paratlan Oláh \& Mey, 2013

(Figures 75-79)

Remarks. In the original description we have compared $T$. paratlan described from Indonesia, Papua, Kecamatan Nipsan, Walmak, to $T$. mondoana Kimmins. It was a mistake. T. paratlan is more close to T. telefominicus Kumanski, 1979 described from the West Sepic Province of Papua New Guinea. Their basic genital architecture is very similar. Both species have paired mesal basodorsal process and its housing ridge on the aedeagus asymmetric. The left mesal basodorsal process revolved vestigial almost lost entirely. The paired lateral ridges or flanges of the aedeagus, housing the curved spiny mesal basodorsal process during rest or in action, also evolved asymmetric; the right ridge is less developed and the downward directed roofing is lost; the left ridge with well-developed roofing, serving its function, together with the less developed right ridge, to hold the paramere analogue in a dorsally fixed pulling or pushing direction.

Triaenodes paratlan and T. telefominicus are closely related incipient sibling species diverged and diverging in the fine structures of those traits that are directly involved in reproductive isolation. The paramere is lost in Triaenodes. In this sibling species pair the paramere function in copulation is taken over by the single mesal basodorsal process of the basal plate of the gonopods. Possible divergences in fine structures between the two species: (1) the internal additional spinelike process on the right mesal basodorsal process is smaller and located on one third subapicad, not long with middle location; (2) the internal additional spine-like process has fine spine-like setae on the tip and along its dorsomesal region, not recognised in T. telefominicus; this microspine row may have dramatic titillating or harming effect during copulation. (3) The shape of the functional right ridge on the aedeagus is differently formed, due probably to the diverged basodorsal process. However, as usual more specimens are required from both species to examine the extent and the stability of divergences.

\section{Triaenodes pellectus Ulmer, 1908}

Material examined. Vietnam, Bach Thai Province, Quang Chu, 24-25.05.1987, light leg. J. Oláh (2 males, 2 females; OPC). Bac Thai Province, Phuluong, Dong Dat, 26.05.1987, light leg. J. Oláh (2 males, 1 female; OPC). 

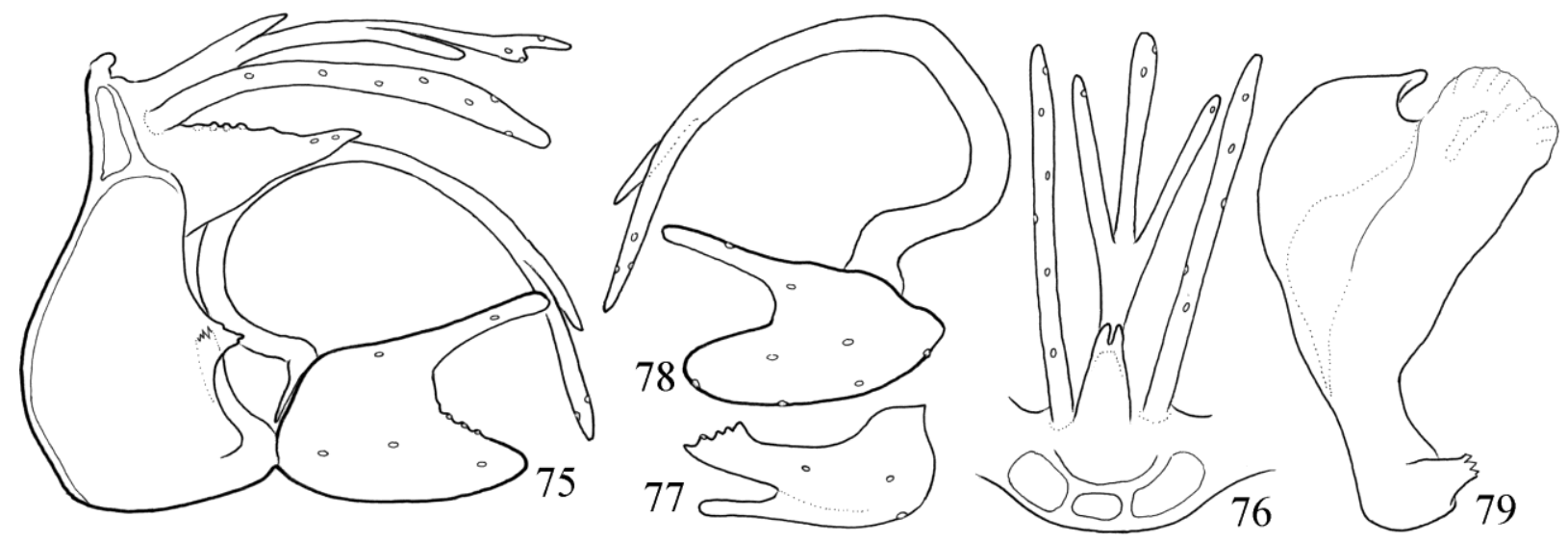

Figures 75-79. Triaenodes paratlan Oláh \& Mey, 2013. Male holotype, $75=$ genitalia in left lateral view, without phallic organ, $76=$ genitalia in dorsal view, 77 = left gonopod in ventral view, 78 = right gonopod with the right mesal basodorsal process in right lateral view, $79=$ phallic organ in left lateral view.

\section{Triaenodes pentheus Malicky, 2005}

Material examined. Vietnam, Moc Chau, 25. 10.1986, light, leg. J. Oláh (1 male, 1 female; OPC).

\section{Triaenodes picinka sp. nov.}

(Figures 80-83)

Diagnosis. Having lobose mesal basodorsal process picinka is close to the speciose T. bernaysae complex of Neboiss \& Wells, but differs by the plate-shaped fused paraproct hooding over the phallic organ.

Material examined. Holotype. Solomon Islands, San Jorge, Casuarina Forest, nr. Stream, vac. Collector, low herbage and litter, 26.09.1965, Royal Soc. Exped. B. M. 1966-1 (1 male, NHM). Paratype. Locality same as of holotype (1 male, OPC).

Description. Male (in alcohol). Brown animal, Scape slightly enlarged, without discernible scent organ; pedicel short, third segment long. Maxillary palp fomula IV-I-II-III-V. Spur formula $1,2,2$. Wing membrane pale yellowish, without any pattern; forewing length $3 \mathrm{~mm}$.

Male genitalia. Segment IX synsclerotized, the subdivided sternum with its posterior partially detached unit giving support to the phallobase by its sclerotized strips. Segment $X$ (upper process of segment $\mathrm{X}$ ) is a short blunt mesal process. Cerci broad, setose foliform, much longer than the abbreviated segment X. Paraproct (lower process of segment $\mathrm{X}$ ) forming a mesal hooding plate over the phallic organ. Gonopods bilobed, apical margin rounded, dorsal lobe small; mesal basodorsal process of the basal plate of gonopods downward curving. Phallic organ forming a slightly curving tube with membranous apex.

Etymology. picinka from "picinyke" very small in Hungarian, refers to very small size.

\section{Triaenodes qinglingensis Yang \& Morse, 2000}

Material examined. Vietnam, Tam Dao, 10.05. 1987 light leg. J. Oláh (1 male, OPC). Bach Thai Province, Quang Chu, 24-25.05.1987, light leg. J. Oláh (4 males, OPC).

\section{Triaenodes ranca sp. nov.}

(Figures 84-87)

Diagnosis. Most close to T. buzoga sp. nov., but differs by having segment $\mathrm{X}$ with wrinkled apex; gonopods short, apical lobes differently shaped; mesal basodorsal process differently shaped, vertically flat and very broad; membranous endotheca more elaborated, especially on dorsum. 

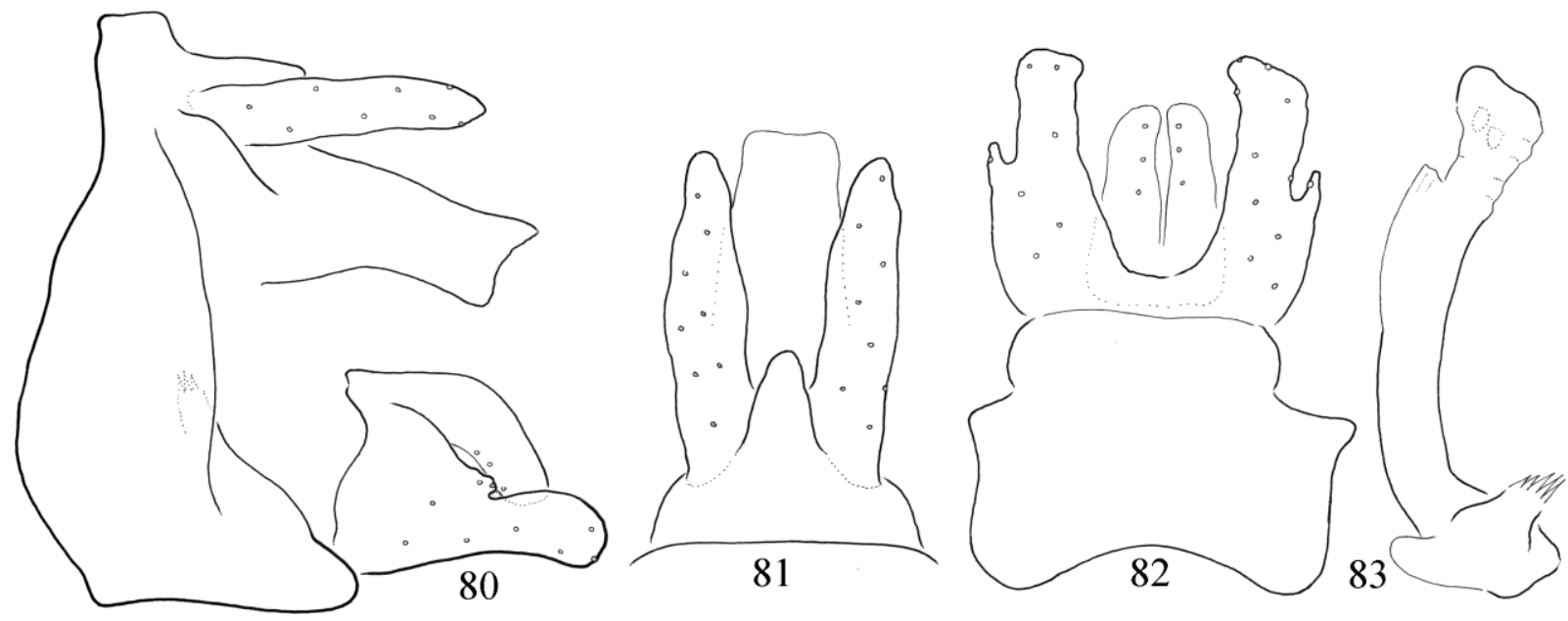

Figures 80-83. Triaenodes picinka sp. nov. Male holotype, $80=$ genitalia in left lateral view, without phallic organ, 81 = genitalia in dorsal view, 82 =genitalia in ventral view, 83 = phallic organ in left lateral view.
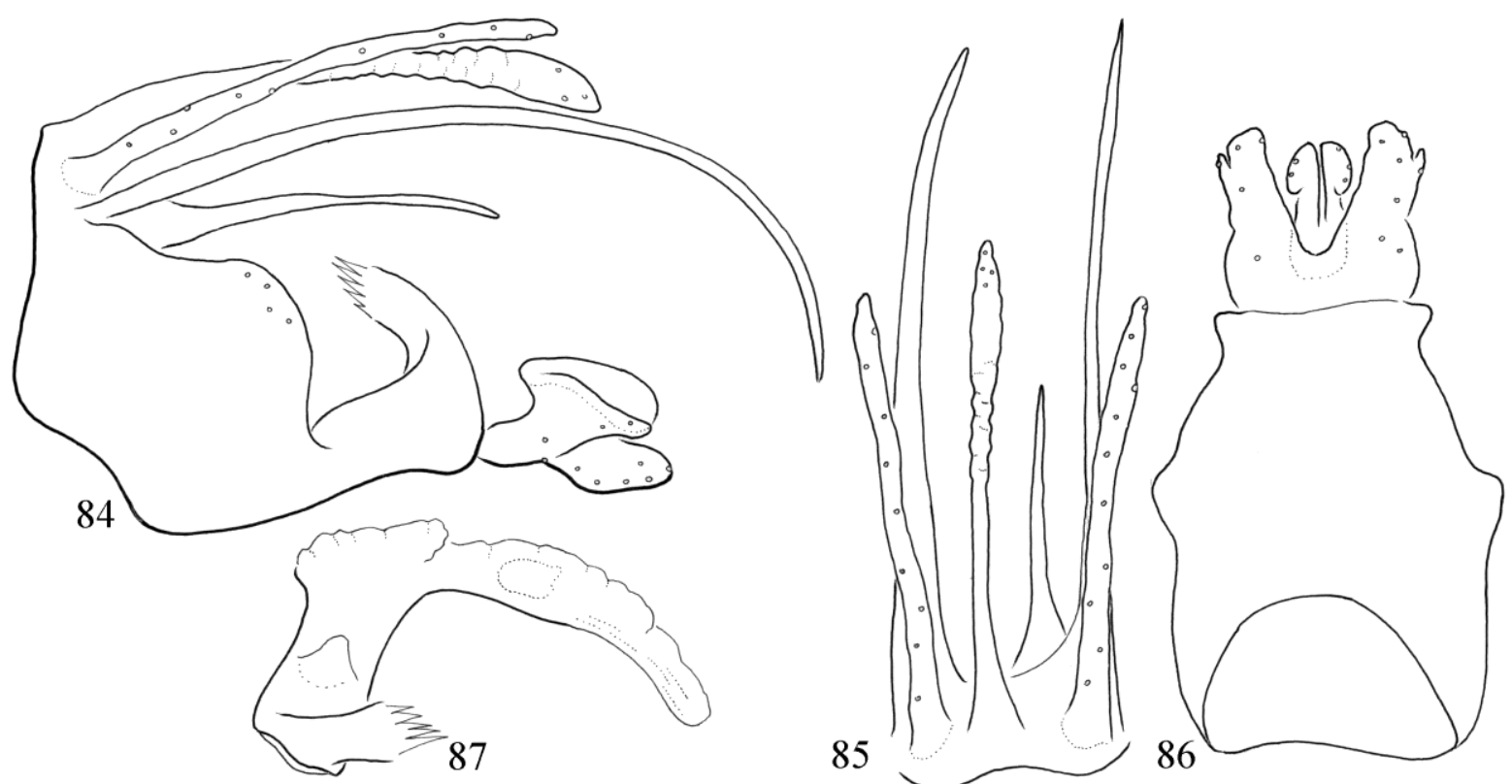

Figures 84-87. Triaenodes ranca sp. nov. Male holotype, 84 = genitalia in left lateral view, without phallic organ $85=$ genitalia in dorsal view, $86=$ genitalia in ventral view, $87=$ phallic organ in left lateral view .

Material examined. Holotype. Fiji Islands, Vanua Levu, Savudvodro Dam, 10.02.1971, leg. G. S. Robinson (1 male, NHM). Paratype. Locality same as of holotype (1 male, OPC).

Description. Male (in alcohol). Brown animal, Scape enlarged, without discernible scent organ; pedicel short, third segment long. Maxillary palp fomula IV-I-II-III-V. Spur formula 1,2,2. Wing membrane pale yellowish, without any pattern; forewing length $8 \mathrm{~mm}$.

Male genitalia. Segment IX synsclerotized, the subdivided sternum with its posterior partially detached unit giving support to the phallobase by its sclerotized strips. Segment $X$ (upper process of segment X) filiform with wrinkled apex. Cerci setose filiform, little shorter than segment $\mathrm{X}$. Paraproct (lower process of segment $\mathrm{X}$ ) forming a 
pair of long filiform spine-like processes. There is a single asymmetric spine like shorter sclerotized pointed process attached to paraproct basement. Gonopods bilobed, ventral lobe enlarged; mesal basodorsal process of the basal plate of gonopods ventrally flat and very broad. Phallic organ forming a downward arching tube with membranous apex and dorsum.

Etymology. ranca from "ránc" wrinkle in Hungarian, refers to the highly wrinkled apex of segment $X$.

\section{Triaenodes sagodii sp. nov.}

(Figures 88-90)

Diagnosis. Similarly to T. triquetra Neboiss \& Wells the segment $X$ is reduced to a short bifid hump. Basic architecture of the genitalia is also similar, but the construction of segment IX, paraproct and gonopods different.

Material examined. Holotype. Indonesia, $\mathrm{Pa}-$ pua Barat, Batanta Island, Northern coast, Waridor River $0^{\circ} 51^{\prime} 53.71 " \mathrm{~S}, 130^{\circ} 31^{\prime} 19.42 \mathrm{E} \mathrm{E}, 18.01$. 2013, light trap, leg R. Horváth (1 male, OPC). Paratypes. Indonesia, Papua Barat, Batanta Island, Northern cost, Waridor River $0^{\circ} 52^{\prime} 6.24 " \mathrm{~S}$, 130³1'30.57"E, 18.01.2013, light trap, leg R. Horváth (1 male, OPC). Papua Barat, Batanta Island, Welebed, waterwork", valley of Kalijakut River, 0'53'22.85'S, 130³8'25.91'E, $105 \mathrm{~m}$, 23.01.2014, UV light-trap, leg. T. Kovács, P.
Juhász, R. Horváth (4 males, OPC). Papua Barat, Batanta Island, Welebed, valley of Kalijakut River, 053'12.88'S, 130 38'16.40”'E, 138m, 23.01.2014, at light, leg. T. Kovács, P. Juhász, R. Horváth (6 males, OPC). Papua Barat, Batanta Island, valley of Waridor River, 0 ${ }^{\circ} 52^{\prime} 09.66$ ”'S, $130^{\circ} 32$ '11.54'"E, 46m, 18.01.2014, at light, leg. P. Juhász, T. Kovács, R. Horváth (4 males, OPC). Papua Barat, Batanta Island, valley of Waridor River, 0 51 '51'S, 130 33'41'"E, 04.02.2015, at light, T. Kovács, R. Horváth, P. Juhász (1 male, OPC).

Description. Male (in alcohol). Pale brown animal. Scape slightly enlarged, with a flap covering an internal cavity with some short yellowish emerging scent setae; pedicel short, third segment long. Maxillary palp formula IV-I-II-III-V. Spur formula 1,2,2. Wing membrane pale yellowish, hyaline window present along anastomosis crossveins; forewing length $4 \mathrm{~mm}$.

Male genitalia. Segment IX fused with shorter tergum, without any discernible suture or groove. Segment $X$ reduced to a short hump with bifid apex. Paraproct plate deeply cleft apicomesad with additional downward curving terminal spines. Cerci setose digitiform in dorsal view, dilated middle in lateral view; half-length of paraproct. Gonopods with long basal stalk and triarmed, plus a very thin filiform process between the two arms. Phallic organ composed of a more sclerotized basal horizontal and a less sclerotized membranous vertical part.
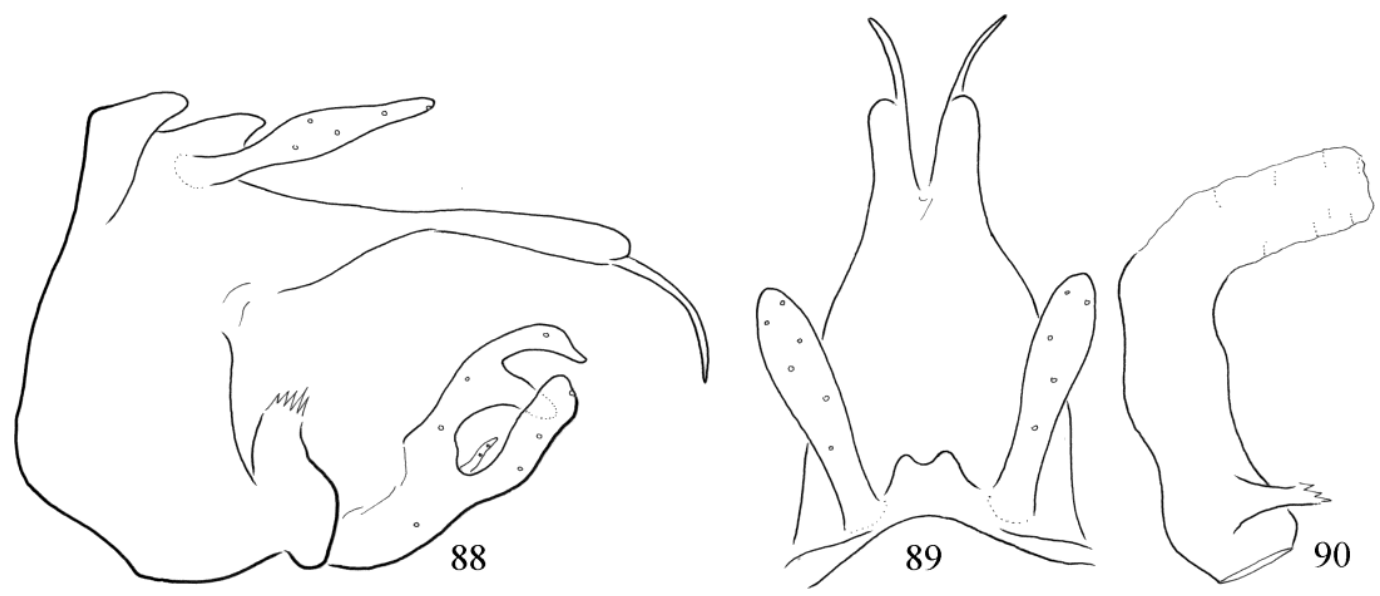

Figures 88-90. Triaenodes sagodii sp. nov. Male holotype, $88=$ genitalia in left lateral view, without phallic organ, $89=$ genitalia in dorsal view, $90=$ phallic organ in left lateral view. 
Etymology. This species is dedicated to Zsolt Ságodi who, as the leader of the Papua Paradise EcoResort (Birie Island) has participated in the field collection on Batanta Island.

\section{Triaenodes sarla sp. nov.}

(Figures 91-93)

Diagnosis. Habitus and genital architecture have similarity to $T$. torpa sp. nov., but wing apices falcate, paraproct with trifid apex in dorsal view and right mesal basodorsal process lost.

Material examined. Holotype. Indonesia, Papua Barat, Batanta Island, Northern coast, Waridor River $0^{\circ} 50^{\prime} 51.04 " \mathrm{~S}, 130^{\circ} 31 ' 10.85 " \mathrm{E}$ under great clearing, 18.01.2013, light trap, leg R. Horváth (1 male, OPC). Paratypes. Indonesia, Papua Barat, Batanta Island, valley of Weras Stream, $0^{\circ} 49^{\prime}$ 51.2"S, $130^{\circ} 38^{\prime} 00.0$ " E, $300 \mathrm{~m}$, 8.02.2015, at light, T. Kovács, P. Juhász (1 male, OPC). Papua Barat, Batanta Island, Kalijakut River, 0'52'49.1'S, $130^{\circ} 38^{\prime} 4.9$ 'E, 16.02.2015, UV light-trap, leg. T. Kovács, P. Juhász, (1 male, OPC). Papua Barat, Batanta Island, Kalijakut River, 0`52'52.0”'S, 130 38'8.0'E, 16.02.2015, at light, leg. T. Kovács, P. Juhász (2 males, OPC).

Description. Male (in alcohol). Small, brown animal. Scape enlarged, scent organ without any setae, the internal cavity of the scape is fully filled with an elongated membranous ovoid swollen structure emerging out through the dorsal longitudinal gap emarginated by more sclerotized longitudinal edges; surface of the swollen structure highly elaborated with fine pattern of densely packed minute granulose and probably perforated elements; pedicel short, third segment long. Maxillary palp broken. Spur formula 1,2,2. Wing membrane pale yellowish, hyaline window present on lower anastomosis; forewing form with falcate apex, forewing length $4 \mathrm{~mm}$.

Male genitalia. Segment IX fused with rounded subtriangular sternum and short tergum, without any discernible suture or groove. Segment $X$ forms a single median process with bifid apex, the fork of bifid apex is more deep in paratype from the Kalijakut River. Paraproct a laterally bellied plate with trifid apex. Cerci setose digitiform, half-length of segment $\mathrm{X}$. Gonopods tapering apicad; curving left mesal basodorsal process present, right process lost; a pair of very thin filiform processes developed on the basal plate of the gonopods. Phallic organ short and high with left ventral and right dorsal flaps; large U-shaped phallotremal sclerite with backward turning apices, located at the anterior border of the membranous endotheca.

Etymology. sarla, from "sarlós" falcate in Hungarian, refers to the falcate forewing apices.

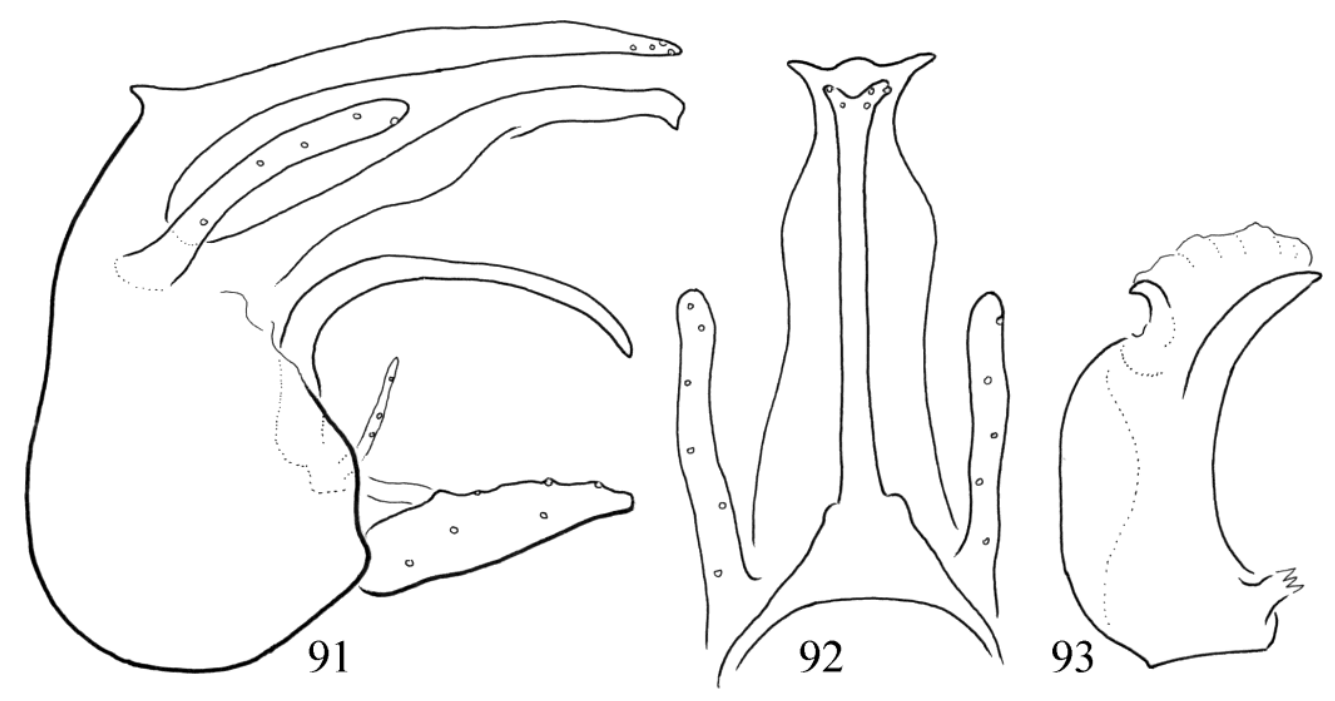

Figures 91-93. Triaenodes sarla sp. nov. Male holotype, $91=$ genitalia in left lateral view, without phallic organ, 92 = genitalia in dorsal view, $93=$ phallic organ in left lateral view. 
Triaenodes sokaga sp. nov.

(Figures 94-97)

Diagnosis. Has similarity to T. patroklos Malicky from Thailand, but differs by much shorter paraproct and the differently shaped gonopods.

Material examined. Holotype. Vietnam, Moc Chau, 25.10.1986 light leg. J. Oláh (1 male, OPC). Paratype. Same as of holotype (1 male, $\mathrm{OPC})$.

Description. Male (in alcohol). Brown animal, Scape slightly enlarged, without discernible scent organ; pedicel short, third segment long. Maxillary palp fomula IV-I-II-III-V. Spur formula $1,2,2$. Wing membrane pale yellowish, without any pattern; forewing length $7 \mathrm{~mm}$.

Male genitalia. Segment IX synsclerotized, the subdivided sternum with its posterior partially detached unit giving support to the phallobase by its sclerotized strips. Segment $X$ (upper process of segment $\mathrm{X}$ ) is a filiform mesal process. Cerci setose filiform, slightly longer than segment X. Paraproct (lower process of segment $\mathrm{X}$ ) forming a single spine-like sclerotized process located right side, accompanied by a small membranous process right side. Gonopods three-lobed; mesal basodorsal process of the basal plate of gonopods downward curving biarmed. Phallic organ form- ing a slightly curving tube with lower left and higher right lateral flanges.

Etymology. sokaga from "sokágú" having many arms or branches in Hungarian, refers to the very complex structure of the gonopods.

\section{Triaenodes sumbana sp. nov.}

(Figures 98-101)

Diagnosis. Has similarity to T. narkissos Malicky, 2005 described from Thailand, but differs by having segment $\mathrm{X}$ short, broad, not broadened apicad; differently shaped gonopods and mesal basodorsal process medium long, not longer than gonopod.

Material examined. Holotype. Indonesia, Sumba, near Lewa, $300 \mathrm{~m}$, small stream with gallery forest, 17.08.2007, light, leg. Z. Ecsedi (1 male, OPC). Paratypes. Locality same as of holotype (2 males, OPC).

Description. Male (in alcohol). Brown animal. Scape enlarged, with discernible scent organ of longitudinal flap covering a longitudinal cavity filled with short setae; pedicel short, third segment long. Maxillary palp fomula IV-I-II-III-V. Spur formula $1,2,2$. Wing membrane pale yellowish, without any pattern; forewing length 7 $\mathrm{mm}$.

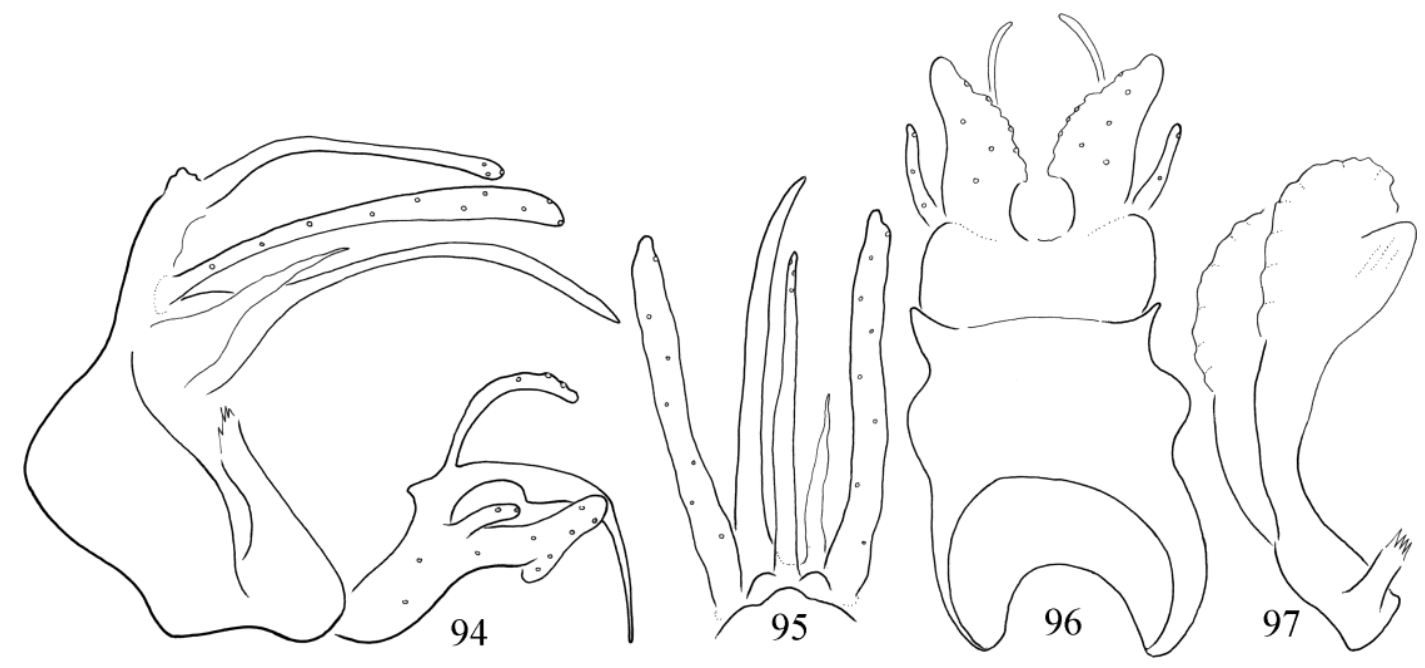

Figures 94-97. Triaenodes sokaga sp. nov. Male holotype, $94=$ genitalia in left lateral view, without phallic organ, $95=$ genitalia in dorsal view, 96 = genitalia in ventral view, 97 = phallic organ in left lateral view. 


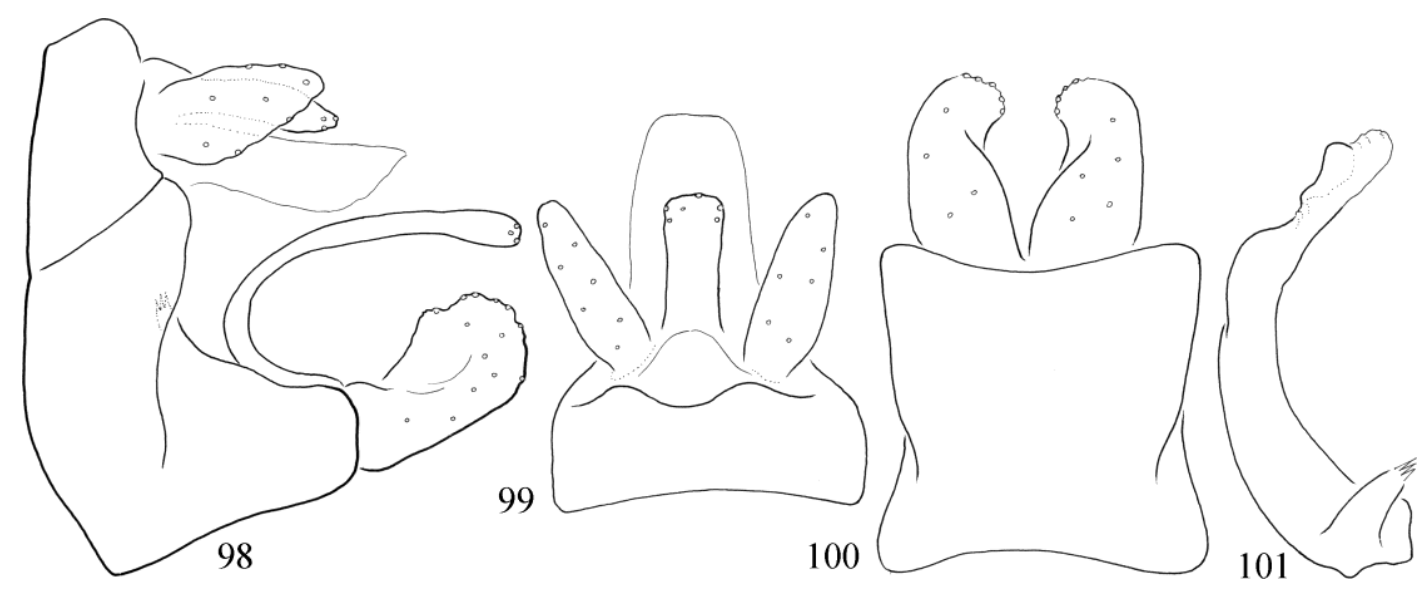

Figures 98-101. Triaenodes sumbana sp. nov. Male holotype, $98=$ genitalia in left lateral view, without phallic organ, $99=$ genitalia in dorsal view, 100 = genitalia in ventral view, $101=$ phallic organ in left lateral view.

Male genitalia. Segment IX synsclerotized with an oblique suture demarking ventrum of tergite IX; the subdivided sternum with its posterior partially detached unit giving support to the phallobase by its sclerotized strips. Segment X (upper process of segment $\mathrm{X}$ ) short and truncated. Cerci short broad foliform. Paraproct (lower process of segment X) fused basally forming a short hood over the phallic organ with indiscernible apex. Apical lobe of gonopods blunt and mesad turning in ventral view. Mesal basodorsal process of the basal plate of gonopods arching. Phallic organ forming a downward curving tube with membranous apex. cality.

Etymology. sumbana, named for the type lo-

\section{Triaenodes tarula sp. nov.}

(Figures 102-105)

Diagnosis. Belongs to the T. intricata species complex and most close to T. nigrolineata Kimmins described from Kokoda, Papua New Guinea, but differs by having very pronounced mesal subapical process covered with stout setae and segment $\mathrm{X}$ without thickened, broad plate.

Material examined. Holotype. Indonesia, Papua Barat, Birdshead Peninsula, Arfak Mountains,

Demaisi, 1637m, $1^{\circ} 10^{\prime}$ 'S, 133 53 'E, 14.11.2011, at light PIF expedition (1 male, OPC).

Description. Male (in alcohol). Long, narrow, brown animal. Scape enlarged, 1.5 times longer than head; scent organ covered dorsally with a long flap; setae below the flap pale, not black; pedicel short, third segment long. Maxillary palp fomula IV-I-(II, V)-III. Spur formula 1,2,2. Wing membrane pale yellowish, without any pattern; forewing length $9 \mathrm{~mm}$.

Male genitalia. Segment IX short, long ventrad, short dorsad, with suture dividing sternum and separating the posterior sternal region of the sclerotized strip supporting the phallobase. Segment $\mathrm{X}$ and paraproct fused, deeply subdivided producing the terminal third directed laterad and a pair of small spines arisen from the bifurcation. Cerci setose horizontally flat, reaching the fork of segment X. Gonopods ending in a triangular capitate lobe in lateral view and characterized by a very long setose mesal subapical process. Mesal basodorsal process bifid. Phallic organ with short phallobase and the aedeagus with very low lateral ridges; phallobase receives a pair of sclerotized strips, this strip rather detached from the ventroapical region of sternite IX, endotheca with a pronounced U-shaped sclerite.

Etymology. tarula, from "tárul" opens in Hungarian, refers to apical region of segment $\mathrm{X}$ with spine-like apices directed laterad. 


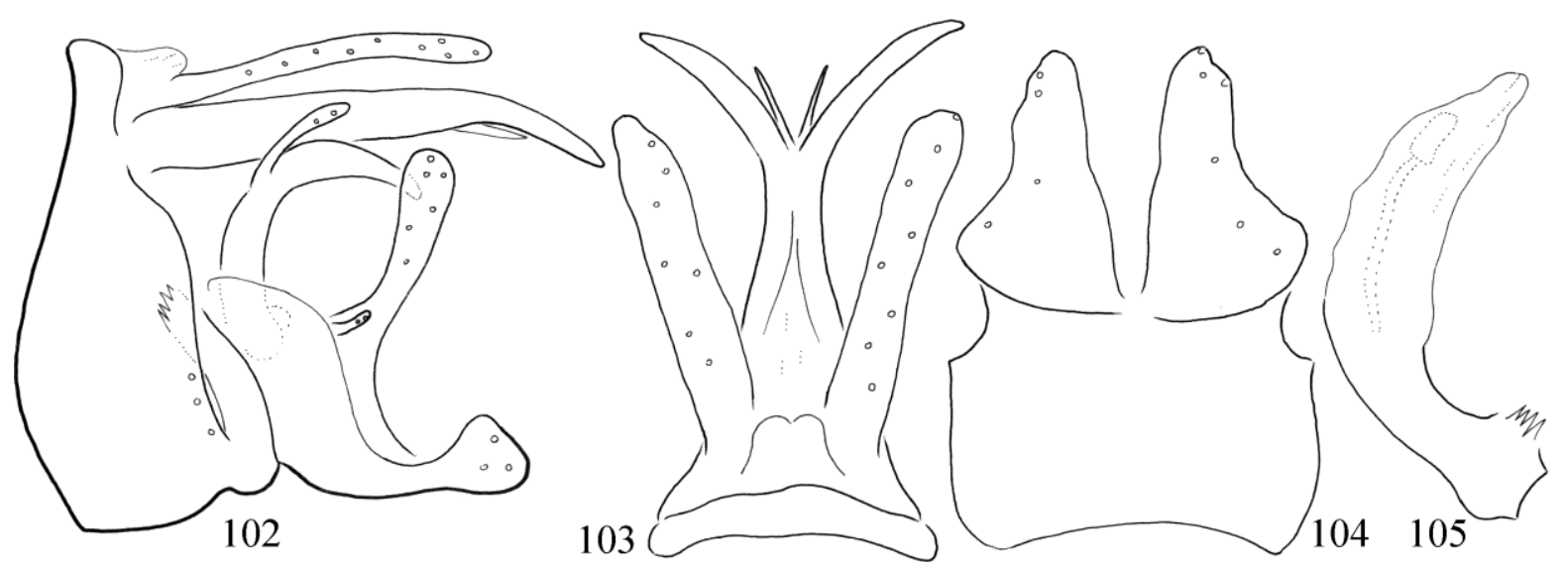

Figures 102-105. Triaenodes tarula sp. nov. Male holotype. $102=$ genitalia in left lateral view, without phallic organ, 103 = genitalia in dorsal view, 104 = genitalia in ventral view, 105 = phallic organ in left lateral view .

\section{Triaenodes torpa sp. nov.}

(Figures 106-109)

Diagnosis. Having a single paramere below the aedeagus this new species is similar to $T$. tafana Kimmins, $T$. thespios Malicky and $T$. marleorum sp. nov., but differs by having paraproct truncate, not excised apicad in dorsal view, lateral profile of gonopods different; lateral basoventral region of paraproct with very elaborated pattern of lobes and fingers, partially present at $T$. tafana, completely lacking at $T$. thespios, at least not recorded.

Material examined. Holotype. Indonesia, Papua Barat, Batanta Island, Northern cost, Warmon stream, 0'50'18.40's, 130²'41.91'"E, above first waterfall, 24.09.2010 light trap, leg R. Horváth (1 male, OPC). Paratypes. Papua Barat, Batanta Island, Northern cost, Warmon stream, $0^{\circ} 50^{\prime} 04.03$ ' 'S, $130^{\circ} 42^{\prime}$ '54.14' $\mathrm{E}$, above first waterfall, 10.06.2010 light trap, leg R. Horváth (6 males, OPC). Papua Barat, Batanta Island, Northern coast, Warmon stream, $0^{\circ} 50^{\prime} 23.25^{\prime \prime} \mathrm{S}$. $130^{\circ}$ 42'35.18'E, below second waterfall, 25.10.2010 light trap, leg R. Horváth (19 males, OPC). Papua Barat, Batanta Island, Northern coast, Warmon stream, $0^{\circ} 50^{\prime} 29.47^{\prime \prime} \mathrm{S}, 130^{\circ} 42^{\prime} 29.16^{\prime \prime} \mathrm{E}$, above second waterfall, 22.01.2013, light trap, leg R. Horváth (21 males, 3 females; OPC). Papua Barat, Batanta Island, Northern coast, Warmon stream, $0^{\circ} 50^{\prime} 8.52$ "S, $130^{\circ} 42^{\prime} 50.4^{\prime \prime} \mathrm{E}$, below first waterfall, 22.01.2013, light trap, leg R. Horváth (5 males, 1 female; OPC). Papua Barat, Batanta Island, Northern coast, Warmon stream, 0 050 '18.40's, $130^{\circ} 42^{\prime} 41.91$ 'E, at fallen tree, 27.01.2012, light trap, leg R. Horváth (2 males, OPC). Papua Barat, Batanta Island, valley of Warmon stream, upper waterfall, $0^{\circ} 50^{\prime} 23.25^{\prime} \mathrm{S}, 130^{\circ} 42^{\prime} 35.18^{\prime \prime} \mathrm{E}, 150 \mathrm{~m}$, 20.01.2014, at light, leg. T. Kovács, P. Juhász (3 males, OPC). Papua Barat, Batanta Island, Kalijakut River, 0'52'52.0'S, 130 38'8.0”'E, 16.02. 2015, at light, leg. T. Kovács, P. Juhász (2 males, OPC).

Description. Male (in alcohol). Small, brown animal. Scape enlarged, with scent organ covered with a long flap; not any setae discernible under the flap; pedicel short, third segment long. Maxillary palp fomula I-IV-II-(III,V). Spur formula $1,2,2$. Wing membrane pale yellowish, hyaline window present on lower anastomosis; forewing length $4.5 \mathrm{~mm}$.

Male genitalia. Segment IX fused with traingular sternum and short tergum, without any discernible suture or groove. Segment X simplified into a single gradually tapering median process with a few tiny emerged setae. Paraproct composed of a quadrangular plate with a median rim hooding the phallic organ and of a pair of lateral lobe with very slender filiform process. Cerci setose digitiform, shorter than segment X. Gonopods with upward curving apex and a small 

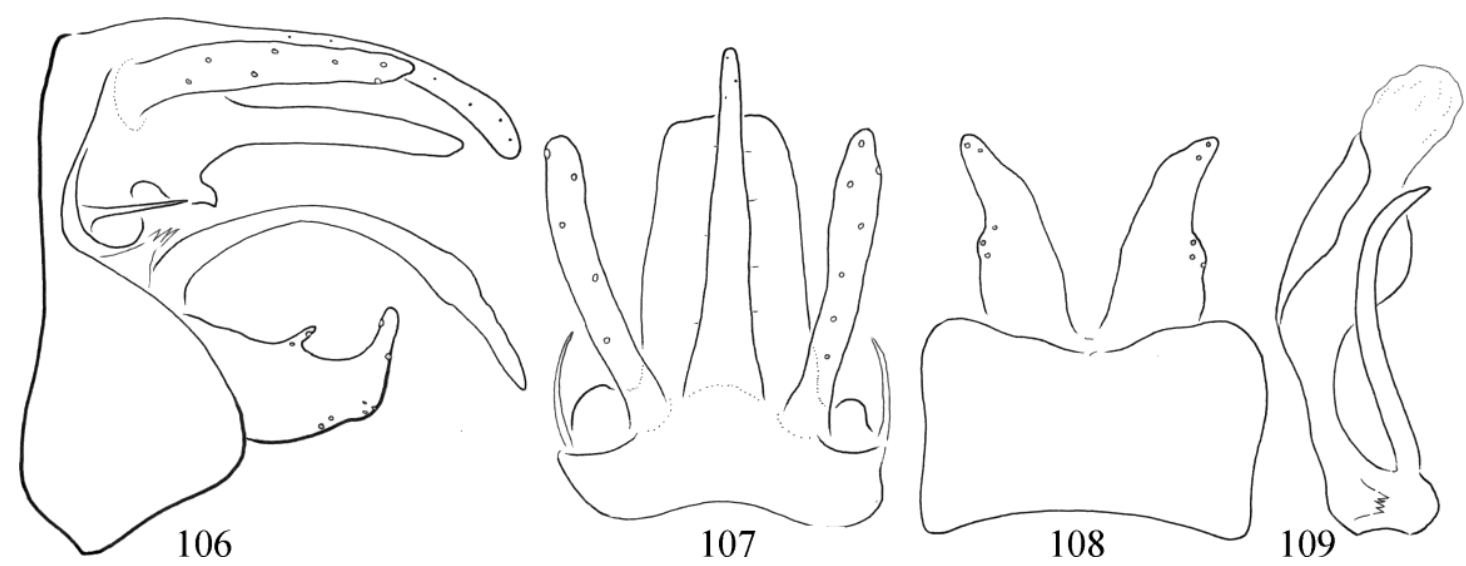

Figures 106-109. Triaenodes torpa sp. nov. Male holotype, $106=$ genitalia in left lateral view, without phallic organ, 107 = genitalia in dorsal view, 108 = genitalia in ventral view, 109 = phallic organ in left lateral view.

digitiform dorsal process middle; spine-like lateral basodorsal process curving with aviform apex. Middle located phallic organ asymmetric with more developed left lateral ridge; a unique single, well developed black spine-like paramere present; (parameres typically lost at Triaenodes) phallobase receives a pair of sclerotized strips, this strip is rather detached from the ventroapical region of sternite IX.

Etymology. torpa, from "törpe" pygmy in Hungarian, refers to the small size of this interesting Triaenodes with paramere on the phallic organ.

\section{Triaenodes tudarda sp. nov.}

(Figures 110-111)

Diagnosis. The basic architecture of the periphallic structures has resemblance to $T$. costalis Kimmins described from Papua (Kokoda), but differs by segment $\mathrm{X}$ short and tapering apicad, not long and widening; gonopod basodorsal branch bifid, not simple spine-like; gonopod ventroapical branch elongated pointed spinelike, not short and truncate. However most remarkable that $T$. costalis has a unique plesiomorphy, a pair of slender blade-like parameres present on the phallic organ. T. tudarda sp. nov., as diagnostic for the genus, has no any paramere.

Material examined. Holotype. Indonesia, Papua Barat, Batanta Island, Northern cost, Warmon stream, $0^{\circ} 50^{\prime} 23.25^{\prime}$ 'S, $130^{\circ} 42^{\prime} 35.18^{\prime \prime} \mathrm{E}$, below second waterfall, 25.10.2010 light trap, leg R. Horváth (1 male, OPC). Paratype: Papua Barat, Batanta Island, Northern cost, Warmon stream, 0 50 '18.40''S, 130 42 '41.91'”, at fallen tree, 27. 01.2012, light trap, leg R. Horváth (1 male, OPC). Papua Barat, Batanta Island, Northern cost, Warmon stream, $0^{\circ} 50^{\prime} 29.47^{\prime \prime S}, 130^{\circ} 42^{\prime 2} 2.16^{\prime \prime} \mathrm{E}$, above second waterfall, 22.01.2013, light trap, leg R. Horváth (1 male, OPC). Papua Barat, Batanta Island, valley of Warmon stram, upper waterfall, 050'23.25”S, $130^{\circ} 42^{\prime} 35.18^{\prime \prime}$ E, $150 \mathrm{~m}, 20.01$. 2014, at light, leg. T. Kovács, P. Juhász (1 male, OPC). Papua Barat, Batanta Island, Northern cost, small stream with dry mouth: $0^{\circ} 49^{\prime} 27.84$ ''S, $130^{\circ} 38^{\prime \prime} 45.02$ "E, 1000-1500m above dry mouth, 28.01.2012, light trap, leg R. Horváth (18 males, OPC). Papua Barat, Batanta Island, between Arefi and Teluk Warai, valley of ,dried estuary of a stream", 0 49'42.05”S, 130³8'12.23”'E, 229m, 27.01.2014, at light, leg.T. Kovács, P. Juhász (16 male, OPC). Papua Barat, Batanta Island, Welebed, valley of Kalijakut River, 0 53 '12.88'S, $130^{\circ} 38^{\prime} 16.40$ 'E, $138 \mathrm{~m}, 23.01 .2014$, at light, leg. T. Kovács, P. Juhász, R. Horváth (12 males, OPC). Papua Barat, Batanta Island, valley of Waridor River, 052'09.66”'S, 130³2'11.54'E, 46m, 18.01.2014, at light, leg. P. Juhász, T. Kovács, R. Horváth (1 male, OPC). Papua Barat, Batanta Island, Teluk Warai, stream, $0^{\circ} 50^{\prime} 51.0^{\prime \prime} \mathrm{S}, 130^{\circ}$ 35'14,0”'E, 11.02.2015, at light, T. Kovács, P. Juhász (2 males, OPC). Indonesia, Papua Barat, 
Batanta Island, valley of Weras Stream, $0^{\circ} 49^{\prime}$ 51.2”S, $130^{\circ} 38^{\prime} 00.0$ ”'E, $300 \mathrm{~m}, 08.02 .2015$, at light, T. Kovács, P. Juhász (1 male, OPC). Papua Barat, Batanta Island, Kalijakut River, $0^{\circ} 52^{\prime}$ 49.1'S, 130³8'4.9'E, 16.02.2015, UV light-trap, leg. T. Kovács, P. Juhász, (1 male, OPC).

Description. Male (in alcohol). Brown animal. Scape enlarged, with scent organ covered with a flap; long scent tuft of brown setae originates from below the flap; pedicel short, third segment long. A pair of vertically elongated hump present on pronotum with laterad directed scent setae. Maxillary palp formula is IV-I-II-III-V. Spur formula $1,2,2$. Wing membrane pale yellowish, without any pattern; forewing length $7 \mathrm{~mm}$; hind wing with a very long scent pencil of black setae hold together basally by a strong jugal fold forming a scent pouch by folding the jugal region below.

Male genitalia. Segment IX triangular, long ventrad, short dorsad, subdivided sternum with its posterior partially detached unit giving support to the phallobase by its sclerotized strips. Segment X composed of the mesal filiform upper part as long as the cerci and of the less sclerotized lower part. Cerci setose, filiform. Paraproct forms a pair of long downward arching spine-like process. Gono

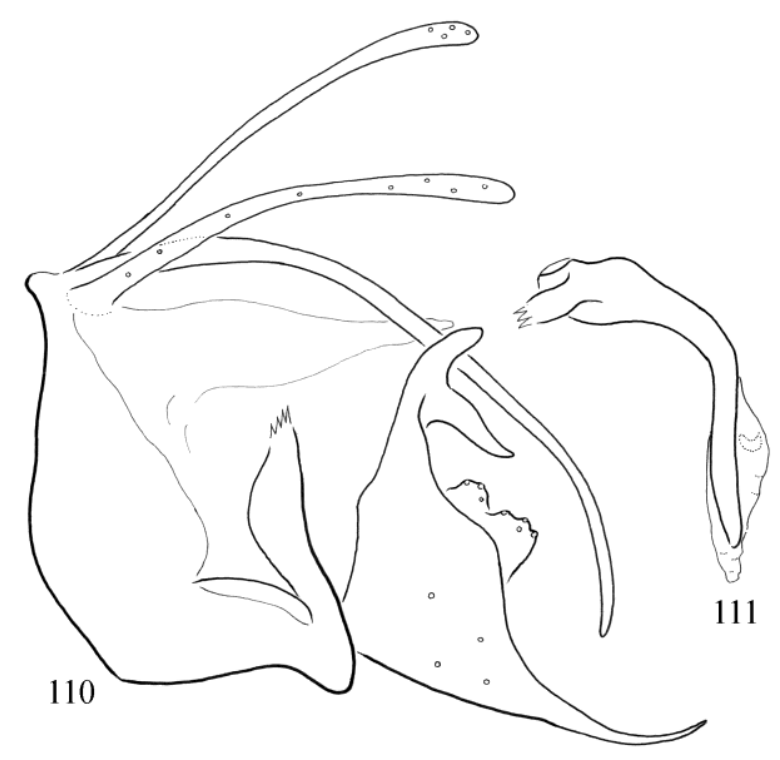

Figures 110-111. Triaenodes tudarda sp. nov. Male holotype, $110=$ genitalia in left lateral view, without phallic organ, $111=$ phallic organ in left lateral view. pods triangular in lateral view with elongated dorsal and apical branches; dorsal branch bifid; apical branch slender pointed, a pair of mesal subapical irregular setose process present. Phallic organ with short phallobase and the aedeagus with low lateral ridges; phallobase receives a pair of sclerotized strips rather detached from the ventroapical region of sternite IX.

Etymology. tudarda, from "tü dárda" pinpointed lance in Hungarian, refers to the slender pin-pointed shape of the apical process on the gonopods.

\section{Triaenodes zicsii sp. nov.}

(Figures 112-115)

Diagnosis. The genitalic structures do not conform to any of the typical arrangement listed by Neboiss \& Wells for Australian species complexes. Similarly to Triaenodes dubia Mosely described from Fiji Island, the segment X (upper part of X) and the paraproct (lower part of X) are fused forming an entirely amalgamated single structure. The new species differs from it by having apices of the fused structures crossed, not parallel-sided long and blade-shaped, the genitalia without any downward curving, centrally situated slender spine, present on $T$. dubia; gonopods apex monolobed, not bifid.

Material examined. Holotype. Indonesia, Papua Barat, Birdshead Peninsula, Arfak Mountains, Mokwam, $1510 \mathrm{~m}, 1^{\circ} 06^{\prime} \mathrm{S}, 1^{\circ} 133^{\circ} 54^{\prime} \mathrm{E}, 6-$ 10.11.2011, at light PIF expedition (1 male, NBCZMAN). Paratype. Indonesia, Papua Barat, Birdshead Peninsula, Arfak Mountains, Demaisi, $1637 \mathrm{~m}, 1^{\circ} 10^{\prime} \mathrm{S}, 133^{\circ} 53^{\prime} \mathrm{E}, 14.11 .2011$, at light PIF expedition (1 male, OPC).

Description. Male (in alcohol). Brown animal. Scape enlarged, with scent organ covered with a long flap; below the closed flap a long black longitudinal structure visible, probably the compressed scent setae; pedicel short, third segment long. Maxillary palp fomula IV-I-V-II-III. Spur formula 1,2,2. Wing membrane pale yellowish, without any pattern; forewing length $7 \mathrm{~mm}$. 


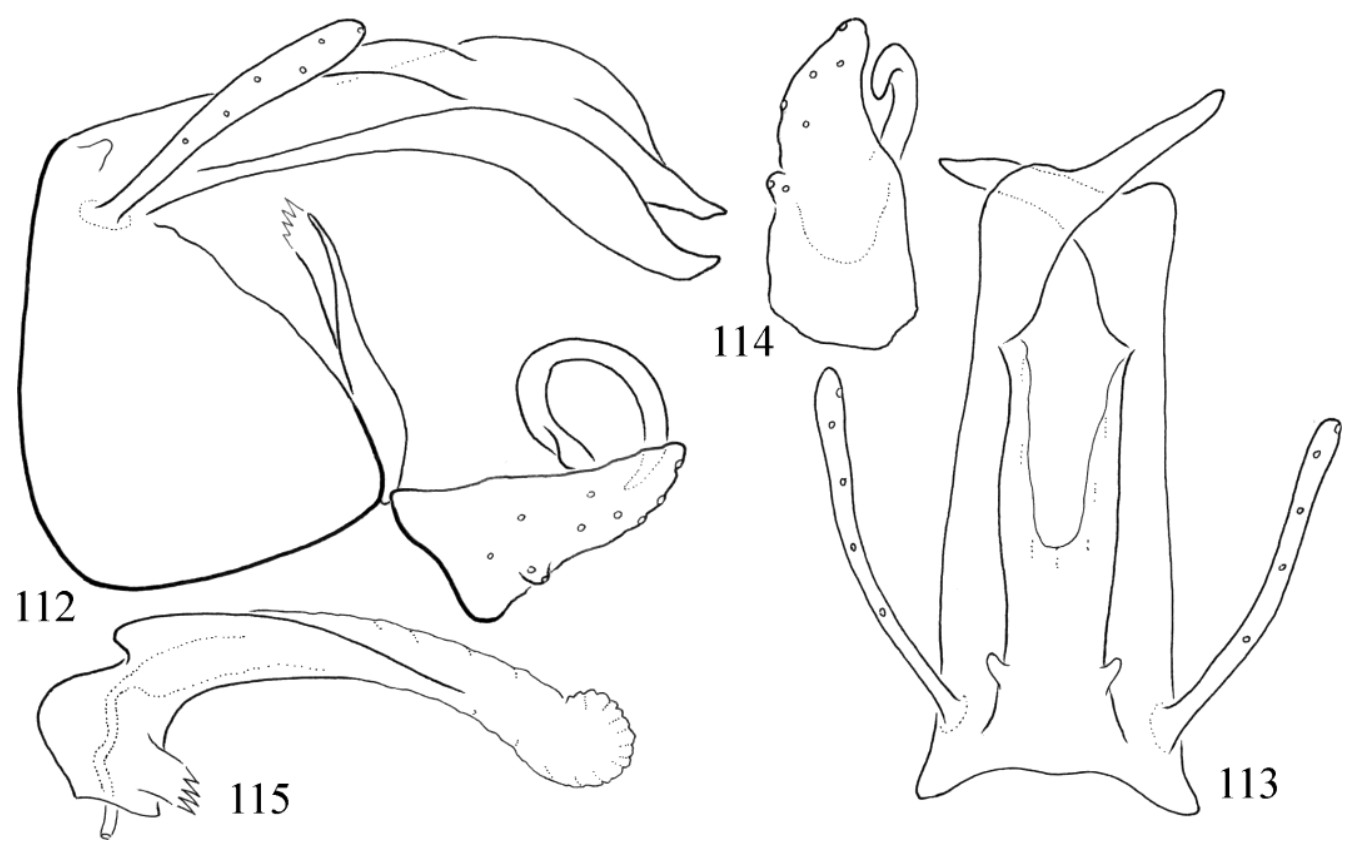

Figures 112-115. Triaenodes zicsii sp. nov. Male holotype, 112 = genitalia in left lateral view, without phallic organ, $113=$ genitalia in dorsal view, 114 = left gonopod in ventral view, $115=$ phallic organ in left lateral view.

Male genitalia. Segment IX triangular, long ventrad, short dorsad, without any discernible suture or groove. Segment X and paraproct fused, deeply subdivided with aviform crossing apices; in the amalgamated complex the segment $\mathrm{X}$ is represented by a pair of vertical dorsal ridges bearing a pair of small gemmiform basal process, the possible vestigium of the lateral processes; the paraproct is represented by the ventral heavily sclerotized pair of long processes with crossing apices. Cerci setose filiform, half as long as the fused segment $\mathrm{X}$ and paraproct. Gonopods triangular in lateral view with a pair of small mesal basodorsal spine-like process curving into a circular shape. Phallic organ with short phallobase and the aedeagus with low lateral ridges; phallobase receives a pair of sclerotized strips rather detached from the ventroapical region of sternite IX.

Etymology. The new species is dedicated to the memory of the late Prof. Dr. András Zicsi the renowned Hungarian soil zoologist and earthworm taxonomist.

\section{Triaenodes zugora sp. nov.}

(Figures 116-119)

Diagnosis. The basic architecture of the genitalia similar to $K$. kalija sp. nov., T. marleorum sp. nov., T. sarla sp. nov., T. tafana Kimmins, $T$. thespios Malicky, T. torpa sp. nov., but differs by having simple paraproct with narrowing pointed apex; by the presence of large mesal subapical lobe on the gonopod; paramere lacking similarly to $T$. sarla sp. nov. and T. kalija sp. nov. Has unique miniaturized left mesal basodorsal process.

Material examined. Holotype. Indonesia, Papua Barat, Batanta Island, Teluk Warai, stream, $0^{\circ} 50 ' 51.0^{\prime \prime} \mathrm{S}, 130^{\circ} 35^{\prime} 14,0^{\prime \prime} \mathrm{E}, 11.02 .2015$, at light, leg. T. Kovács, P. Juhász (1 male, OPC).

Description. Male (in alcohol). Brown animal. Scape enlarged and elongated, almost triple long than head; brown tuft of long scent setae nested on the basodorsal area and recumbent along the entire length of the scape; pedicel short, and third 


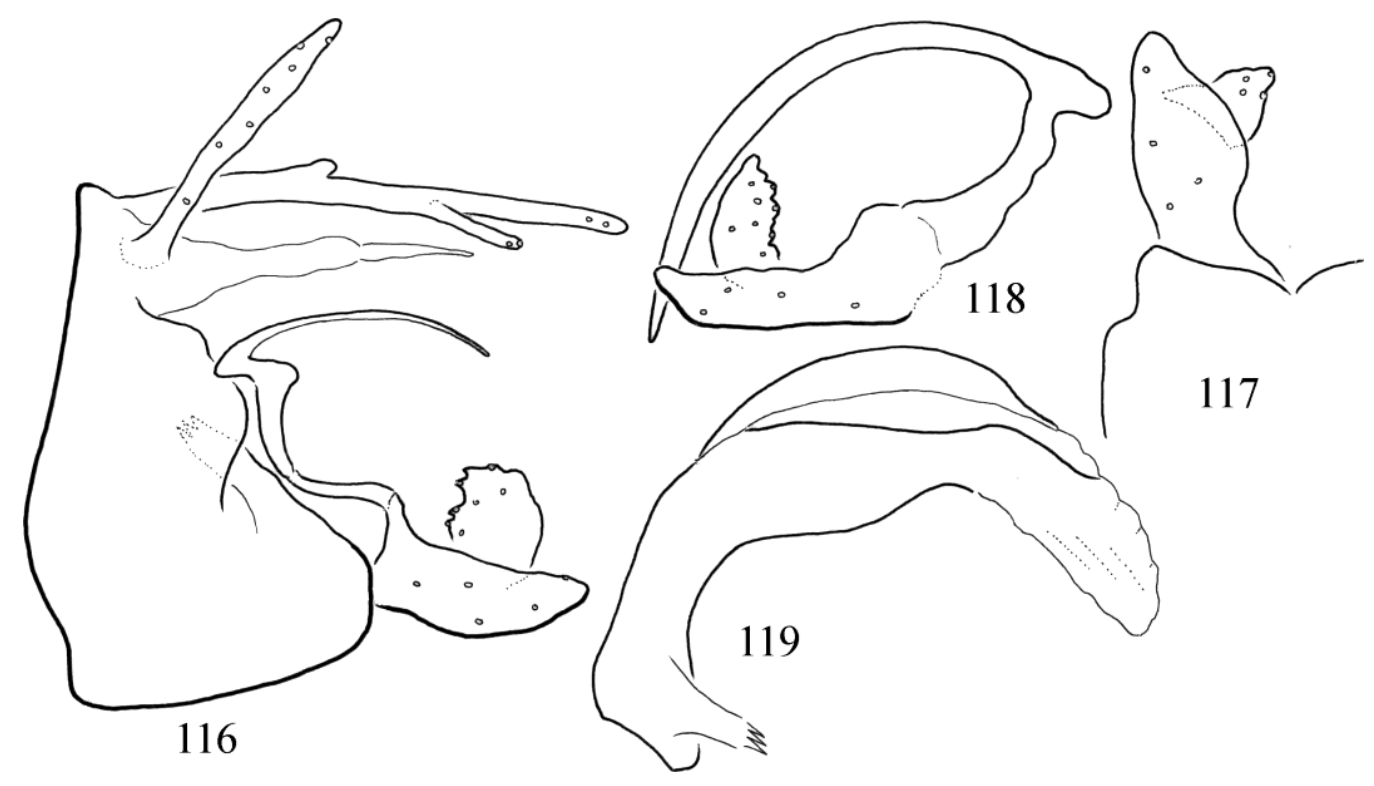

Figures 116-119. Triaenodes zugora sp. nov. Male holotype. $116=$ genitalia in left lateral view, without phallic organ, $117=$ left gonopod in ventral view, $118=$ right gonopod with mesal basodorsal process originates on basal plate, $119=$ phallic organ in left lateral view.

segment long. Maxillary palp fomula IV-I-II-IIIV. Spur formula $1,2,2$. Wing membrane brown, hyaline window present along crossveins of the anastomosis; forewing length $5 \mathrm{~mm}$.

Male genitalia. Segment IX fused with traingular sternum and short tergum, without any discernible suture or groove. Segment $X$ present as a single mesal process with a short bifid dorsal arm midway and a pair of little longer lateral process at two thirds. Paraproct forming a broad based plate hooding the phallic organ, with tapering apex. Cerci setose digitiform, shorter than segment X. Gonopods subtriangular in lateral view with large mesal subapical setose lobe; a pair of spine-like mesal basodorsal process originnates on basal plate of gonopods with vertical stalk than curving posterad enforced by a short anterior knot; left process miniaturized. The phallotheca of the middle located phallic organ produced a pair of laterad than downward directed dorsolateral rim housing the mesal basodorsal processes; left low, and longer housing the miniaturized left process; right more developed, high housing the right process; phallobase receives a pair of sclerotized strips from the ventroapical region of segment IX.
Etymology. zugora, from "zsugor" shrink in Hungarian, refers to the reduced, vestigial size of the left mesal basodorsal process on the basal plate of the gonopods.

\section{REFERENCES}

MALICKY, H. (2005): Beitrage zur Kenntnis asiatischer Triaenodes McLachlan 1865 (Trichoptera, Leptoceridae). Zeitschrift der Arbeitsgemeinschaft Österreichischer Entomologen, 57: 33-46.

Neboiss, A. \& Wells, A. (1998): Review of Australian species of Triaenodes McLachlan (Trichoptera: Leptoceridae). Memoirs of the Museum of Victoria, 57(1): 89-132.

OlÁH, J. (2012a): Taxonomic list of Trichpoptera described and recorded from New Guinea region. Folia Historico Naturalia Musei Matraensis, 36: 105-122.

OLÁH, J. (2012b): New species and records of Trichoptera from Batanta and Waigeo Islands (Indonesia, Raja Ampat Archipelago, Papua (Irian Jaya). Braueria, 39: 39-57.

OLÁH, J. (2013): On the Trichoptera of Batanta Island (Indonesia, West Papua, Raja Ampat Archi- 
pelago). Folia Entomologica Hungarica, 74: 21-78.

OLÁH, J. (2014): On the Trichoptera of Batanta Island (Indonesia, West Papua, Raja Ampat Archipelago), III. Folia Entomologica Hungarica, 75: 91-131. doi: 10.17112/FoliaEntHung.2014.75.91

OLÁH, J. (2015): On the Trichoptera of New Guinea. Folia Entomologica Hungarica, 76: in press.

OlÁH, J. \& MEY, W. (2013): New species of caddisflies from New Guinea (Insecta, Tricho- ptera). Entomofauna. Zeitschrift für Entomologie, 34(31): 409-432.

OlÁH, J. \& KovÁCS, T. (2015): On the Trichoptera of Batanta Island (Indonesia, West Papua, Raja Ampat Archipelago) IV. Folia Historico Naturalia Musei Matraensis 39: in press.

SCHMID, F. (1965): Quelques Trichopteres de Chine II. Bonner zoologische Beitrage, 16(1-2): 127-154.

Ulmer, G. (1908): Japanische Trichopteren. Deutsche entomologische Zeitschrift, 1908: 339-355. 